\title{
CUANTIFICACIÓN ANATÓMICA Y DISPERSIÓN ESPACIAL DE RESTOS HUMANOS DEL SITIO LAGUNA TRES REYES 1 (ÁREA INTERSERRANA BONAERENSE)
}

\author{
Mariela E. González \\ CONICET-INCUAPA, Departamento de Arqueología, Facultad de Ciencias Sociales (UNCPBA). \\ Av.Del Valle5737 (B7400JWl), Olavarría.E-mail:mgonzalez@soc.unicen.edu.ar.
}

Presentado: 10/04/08 - Aceptado: 20/08/08

\section{Resumen}

En este trabajo se presentan los resultados obtenidos a través del análisis cuantitativo y de dispersión espacial sobre el registro bioarqueológico del sitio Laguna Tres Reyes 1 (partido de Gonzales Cháves). Los fechados radiocarbónicos realizados sobre restos humanos y faunísticos ubican cronológicamente al sitio en el Holoceno tardío. Ambos tipos de análisis se realizaron con el fin de obtener valores útiles para examinar la integridad anatómica del conjunto de entierros y los porcentuales de supervivencia de cada unidad ósea; así como para evaluar las distancias recorridas por los huesos desplazados, establecer las relaciones anatómicas con las partes esqueletarias correspondientes y reconocer si existe una tendencia en la clase de huesos dispersos. Los resultados obtenidos contribuyen a la reconstrucción de la trayectoria tafonómica recorrida por estos restos óseos humanos. En referencia a los índices cuantitativos, se concluye que el conjunto de entierros humanos de TR1 presenta un alto grado de representación diferencial en relación con la integridad esqueletal. Respecto del índice de supervivencia, sólo el 35\% del total de huesos esperados está presente en esta muestra. Este bajo porcentaje indica la acción de uno o más factores tafonómicos que inciden en la configuración actual de este registro. No obstante este alto índice de pérdidas de partes esqueletarias, debe destacarse la excelente preservación del tejido óseo en la gran mayoría de los huesos.

Palabras claves: entierros primarios, cazadores-recolectores, análisis cuantitativos, formación del registro bioarqueológico.

\begin{abstract}
This paper presents the results of the quantitative and spatial analyses carried out on the bioarchaeological record of the site Laguna Tres Reyes 1 (Buenos Aires Province, Argentina). The radiocarbon dating on human and faunal remains locates chronologically this site in the late Holocene. Both kinds of analyses were done, on the one hand, with the purpose of evaluate the anatomical integrity of the burials and the percentages of survivorship of each bone unit; and on the other hand, to evaluate the distance covered by the displaced bones and the anatomical relationships with the corresponding skeletal parts and to determine if exist any tendency in the class of dispersed bones. The results of these analyses contribute to the reconstruction of the taphonomic history of the human remains at the site. In relation to the skeletal integrity, the quantitative study supports the conclusion that the set of human burials at TR1 presents a high degree of differential survivorship. Only 35\% of
\end{abstract}


the expected bones are present in the sample. This low percentage indicates the action of one or more taphonomic factors affecting the present configuration of this record. Despite this high index of losses of skeletal parts, the excellent preservation of the bones tissues in the great majority of the bones must be pointed out.

Keywords: Primary burials, hunter-gatherers, quantitative analysis, formation of bioarchaeological record.

\section{Introducción}

Las características y condiciones de los restos arqueológicos están influenciadas y condicionadas por una serie de variables correspondientes a diferentes esferas de actividad. Por un lado, todas las acciones realizadas en el pasado dentro de un contexto sistémico (Schiffer 1972, 1987), durante la formación original del registro. Por otro, todos los procesos naturales y culturales actuantes desde el momento de la depositación de los restos hasta su recuperación actual. Por tanto, las interpretaciones planteadas desde la arqueología deben partir de una evaluación integral de los factores y procesos que contribuyeron a la conformación del registro arqueológico estudiado (Kligmann 1998). Distinguir de qué modo y con qué variabilidad responden los restos óseos ante los distintos procesos y agentes que interactúan con ellos contribuye a la generación de conocimiento relevante para entender la trayectoria tafonómica del conjunto y para generar explicaciones de las conductas humanas.

Para el caso de los restos óseos humanos, la posibilidad de construir su historia tafonómica es fundamental debido al amplio potencial que éstos poseen para la generación de conocimiento sobre diversos fenómenos culturales, ecológicos y conductuales que involucraron a los grupos humanos del pasado (O'Shea 1984; Carr 1995). En este sentido, se considera que las diferentes temáticas relacionadas a los procesos de formación del registro arqueológico deben ser consideradas y evaluadas, siempre que sea posible, en toda interpretación derivada del análisis del registro biológico humano (González 2006, 2007).

En este trabajo se presentan los resultados concernientes a los aspectos cuantitativos examinados en el marco de una investigación más amplia destinada a evaluar los procesos tafonómicos que habrían afectado al conjunto de entierros humanos primarios pertenecientes al sitio arqueológico Laguna Tres Reyes 1 ubicado en el partido de Adolfo Gonzales Chaves, provincia de Buenos Aires (ver González 2007). Este sitio ha sido asignado al Holoceno tardío a través de una serie de fechados radiocarbónicos (Madrid y Barrientos 2000). La estimación de los desplazamientos verticales y horizontales de los elementos óseos ocurridos dentro del paquete sedimentario junto con la estimación de los cambios en las relaciones anatómicas, ha aportado un cuerpo de conocimiento relevante para el entendimiento de la historia tafonómica de este registro bioarqueológico. De este modo, se pudieron determinar distintos índices de representación de piezas esqueletarias y la integridad de los diferentes individuos representados así como establecer el grado de faltantes óseas generadas por los distintos agentes y procesos actuantes sobre los restos óseos humanos. En relación con estos aspectos cuantitativos, se evaluaron los tipos de procesos que provocaron mayores efectos de desplazamiento y las consecuencias que éste tuvo para la conformación final del conjunto óseo. En consecuencia, los resultados obtenidos mediante este tipo de análisis permiten ajustar más estrechamente las inferencias arqueológicas respecto de las conductas humanas del pasado a las distintas evidencias que aportan los huesos humanos. 


\section{Ubicación del sitio}

La Localidad Arqueológica Laguna Tres Reyes se encuentra localizada sobre las márgenes de la laguna homónima a $37^{\circ} 56^{\prime} 10^{\prime \prime}$ de Latitud Sur y a 60 34' 23' de Longitud Oeste (Carta Topográfica "Pedro P. Lasalle", IGM 3760-32-4, 1953, E: 1:50.000), en el partido de Adolfo Gonzáles Cháves, provincia de Buenos Aires (Madrid y Barrientos 2000). La misma se halla en el sector centro-sur del área Interserrana Bonaerense (Figura 1). La Laguna Tres Reyes es un cuerpo de agua permanente con una extensión de aproximadamente 450 ha., situada a ca. $15 \mathrm{Km}$. al sudoeste de las nacientes del río Quequén Salado (Madrid y Barrientos 2000).

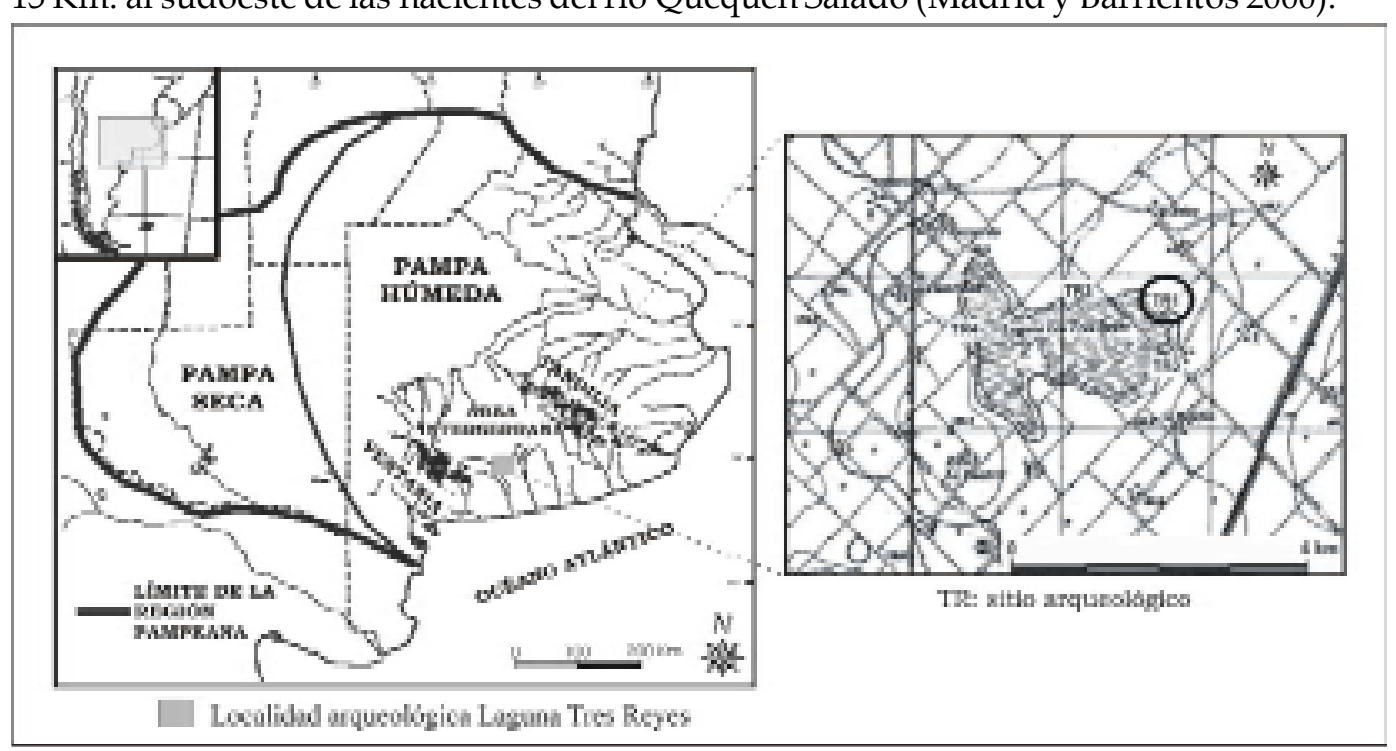

Figura 1. Ubicación del área interserrana y del sitio TR1

Dentro de esta localidad, se han descubierto hasta el presente 4 sitios arqueológicos a cielo abierto (TR1, TR2, TR3 y TR4) (Figura 1), de los cuales sólo TR1 ha sido excavado e investigado sistemáticamente y su registro bioarqueológico es el objeto de análisis en este trabajo.

\section{Características geológicas}

En el depósito sedimentario del sitio TR1 se diferenciaron tres unidades estratigráficas (Figura 2) en diferentes sectores de la barranca de la laguna (Politis y Madrid 1988; Madrid et al. 1991; Madrid y Salemme 1991): Unidad A, B, y C (UE A, B, C). La Unidad A (0,25 a 0,40 $\mathrm{m}$ de espesor) está compuesta por un sedimento arenoso, gris oscuro, correspondiente al suelo actual. Hacia la base presenta pequeñas concreciones de carbonato de calcio, pasando gradualmente a la unidad siguiente a través de una zona de transición denominada A/B. En esta unidad y en la zona de transición A/B se han recuperado artefactos líticos, alfarería y restos óseos, principalmente de guanaco (Lama guanicoe) y venado de las pampas (Ozoteceros bezoarticus) (Madrid et al. 1991; Salemme y Madrid 2007). La Unidad B (0,15 a 0,35 m de espesor) presenta un sedimento eólico marrón oscuro con alto contenido de carbonato de calcio, presentando concentraciones de nódulos de carbonato de calcio hacia la base, esta zona se denomina B Carbonato. En esta unidad se registraron artefactos líticos, un alto 
porcentaje de restos de guanaco y, en menor proporción, de venado de las pampas (Madrid et al. 1991; Madrid y Barrientos 2000; Salemme y Madrid 2007). Estas dos primeras unidades estratigráficas son asignables a la parte más joven de la Formación La Postrera (sensu Tonni y Fidalgo 1978). La Unidad C contiene sedimento limo-arenoso, gris blanquecino con nódulos de tosca que forma la base de la secuencia estratigráfica. Esta unidad representa al Miembro Guerrero de la Formación Luján (sensu Tonni y Fidalgo 1978). Entre las unidades estratigráficas $\mathrm{B}$ y $\mathrm{C}$ se ha identificado una discordancia erosiva. Existen evidencias estratigráficas en la base de la Unidad B que indican fluctuaciones en el nivel de la laguna. Como consecuencia, se habría producido el retrabajo y redepósito de los sedimentos y transporte de carbonatos (Gutierrez 2004).

Si bien se recuperaron materiales arqueológicos en todo el espesor del depósito, el análisis de su distribución espacial, las características tecno-morfológicas, el estado de conservación y el grado de perturbación posdepositacional de los conjuntos, permitieron definir 2 unidades arqueológicas discretas: Componente Superior (CS) (Salemme 1987; Madrid y Salemme 1991) y Niveles Inferiores (NI) (Madrid et. al. 1991). El CS está localizado en la UE A y en la zona de transición A/B, mientras que los NI se localizan en la UE B y C. Como resultado de las últimas observaciones realizadas, Madrid y Barrientos (2000) consideran que la definición estratigráfica del Componente Superior (CS) debería incluir a los materiales recuperados en la parte superior de la UE B debido a que los restos allí encontrados podrían haber migrado verticalmente desde la UE A como resultado de la acción de mamíferos cavadores principalmente.

\section{Antecedentes de investigación y excavación}

En el año 1994, debido al hallazgo casual por parte de aficionados de un cráneo y huesos humanos aislados cerca de las cuadrículas abiertas en excavaciones previas, se retoman las prospecciones y excavaciones. Durante diciembre de dicho año y marzo-abril de 1995 se excavaron 3 cuadrículas (C12, C13 y C14) sobre la línea de barranca (Figura 3). Se diferenciaron las 3 unidades estratigráficas anteriormente mencionadas (UE A, B y C), y sólo en dos de ellas (A y B) se recuperaron artefactos líticos, cerámica y restos arqueofaunísticos. En la cuadrícula 12 se halló un conjunto de restos óseos humanos correspondientes a un mínimo de 10 individuos (Figura 4) (Madrid y Barrientos 2000).

Los estudios desarrollados demuestran que los conjuntos arqueológicos provenientes del Componente Superior (UE A y transición A/B) corresponden a un nivel de ocupación humana caracterizada por un grupo con una economía cazadora-recolectora que llevaron a cabo actividades múltiples en el sitio (Politis 1988; Madrid y Salemme 1991; Madrid et al. 1991; Salemme y Madrid 2007).

\section{Cronología}

Hasta el presente se han realizado 5 fechados radiocarbónicos para ubicar cronológicamente al sitio TR1. De estos, 3 corresponden a fragmentos óseos de guanaco provenientes de las unidades estratigráficas A y B y 2 a huesos humanos (Homo sapiens: $2.245 \pm 55 \mathrm{AP} ; 2.470 \pm 60 \mathrm{AP}$ ) (Tabla 1). Los resultados de los fechados sobre el registro arqueofaunístico no se corresponden con la procedencia estratigráfica del material datado. 


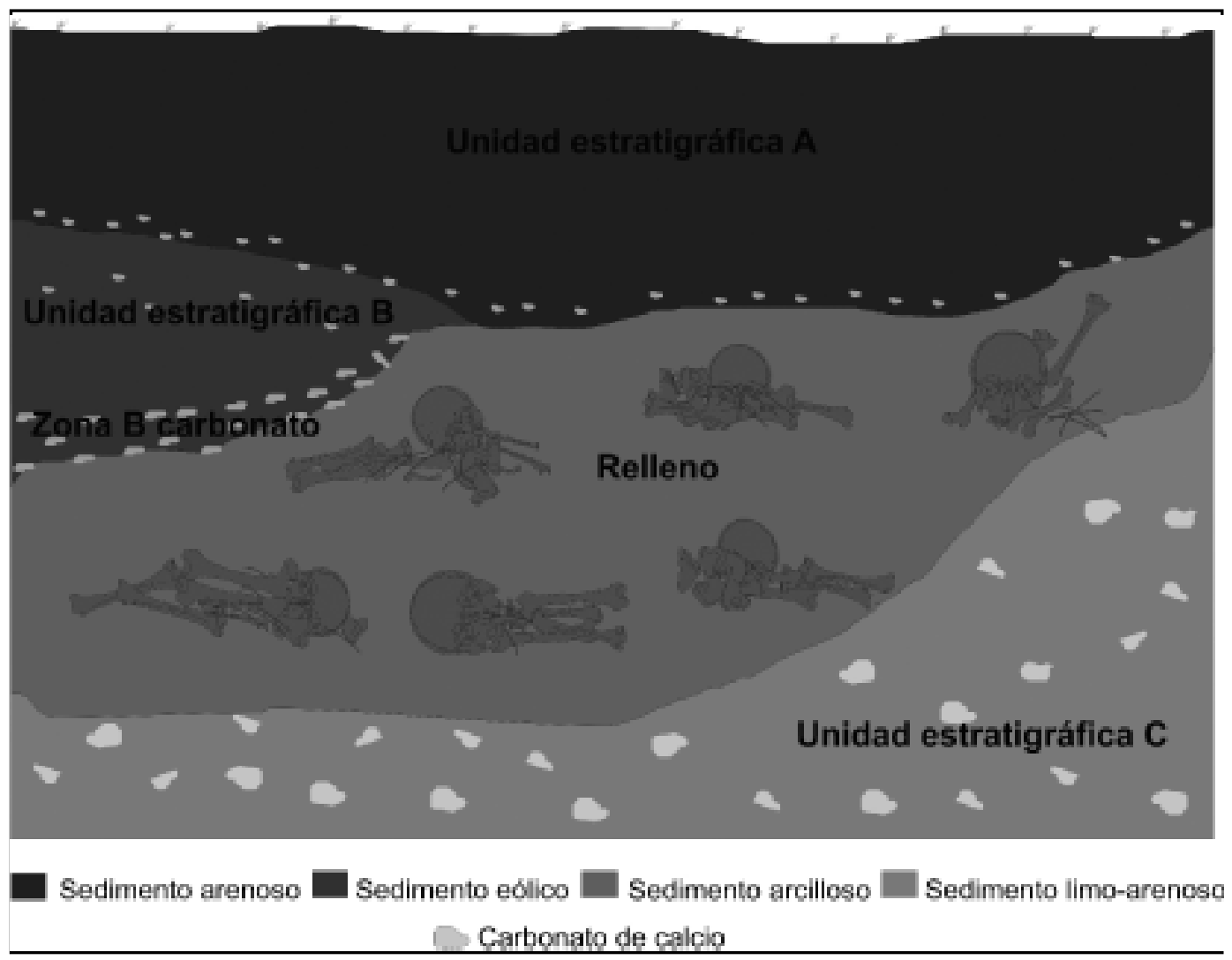

Figura 2. Esquema del perfil estratigráfico de TR1

(Las posiciones de los esqueletos son sólo ilustrativas).

Madrid y Barrientos (2000) señalan las incongruencias encontradas en algunos fechados y sostienen que la migración vertical es la causa de estas incongruencias.

\section{El registro bioarqueológico de TR1}

Se recuperaron, en la cuadrícula 12, restos óseos humanos correspondiente a un mínimo de 10 individuos $(\mathrm{NMI}=10)$ de distinto sexo y edad: 6 adultos y 4 sub-adultos; el grupo adulto de la muestra está integrado por 4 individuos masculinos y 2 femeninos (Barrientos 1997; González 2006). Según Madrid y Barrientos (2000), este registro bioarqueológico representa un entierro múltiple de carácter primario (TR1-1 al TR1-9) superpuesto a un evento de inhumación primario previo (TR1-10). Las unidades estratigráficas distinguidas aquí son consistentes con las ya descriptas para otros sectores del sitio (UE A, A/B, B y C). No obstante, los restos óseos humanos se hallaron dentro de un sedimento color marrón oscuro con un alto contenido de arcillas, muy diferente de las unidades estratigráficas mencionadas (Madrid y Barrientos 2000). Este sedimento sería intrusivo en la secuencia estratigráfica local constituyendo el relleno del pozo de inhumación (Barrientos com. personal 2004).

Las dimensiones aproximadas del pozo que contenía los restos son: largo máximo: 2,10 m (dirección: E-O), ancho máximo: 1,65 m (dirección: N-S), espesor: 0,40 m. Los restos 


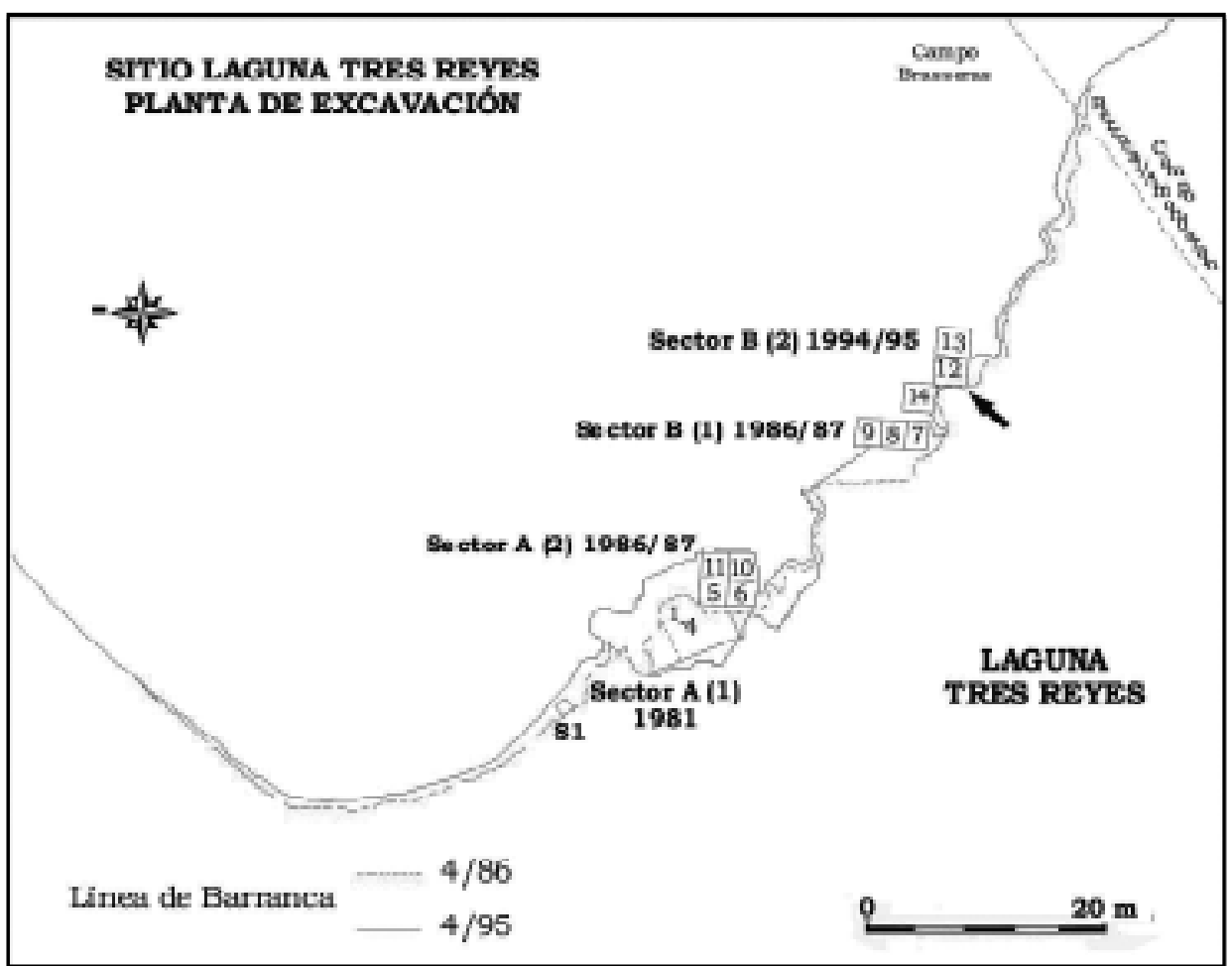

Figura 3. Distribución de las cuadrículas excavadas durante los diferentes periodos de trabajo de campo. (La flecha señala la cuadrícula donde se hallaron los entierros humanos). Modificado a partir de Gutierrez 2004.

correspondientes a tres esqueletos que se hallaron a mayor profundidad (TRI-6, TRI-9, y TRI10) se encontraban sobre una formación de tosca que constituye la base de la secuencia estratigráfica (UEC). No se recuperó ningún elemento cultural asociado en forma directa a los restos óseos humanos (Madrid y Barrientos 2000).

Los resultados obtenidos mediante la datación radiocarbónica en esta muestra humana (Tabla 1) parecen apoyar la proposición de al menos dos eventos de inhumación en el lugar. El más antiguo estaría representado por el esqueleto TRI-10 y el resto de los individuos representaría el más reciente (Madrid y Barrientos 2000).

\section{Materiales y métodos}

Los objetivos particulares que guiaron el presente trabajo fueron: a) realizar análisis cuantitativos básicos (NMI, NME, NISP) que permitieran I) precisar el porcentaje de elementos óseos representados por cada esqueleto, II) conocer el número total de unidades óseas y de individuos representados, III) reconocer el grado de fragmentación de los materiales, IV) establecer correlaciones entre los índices obtenidos y la densidad mineral ósea, y b) evaluar las disposiciones de los elementos óseos mediante la revisión de los mapeos de campo y las fotografías del sitio, teniendo en cuenta los desplazamientos horizontales y verticales y la posición estratigráfica. Estos análisis formaron parte de un estudio tafonómico mayor en el cual se llevaron a cabo otra serie de tareas específicas sobre los restos óseos humanos de TR1 (para una síntesis de los efectos tafonómicos registrados ver González 2007). 


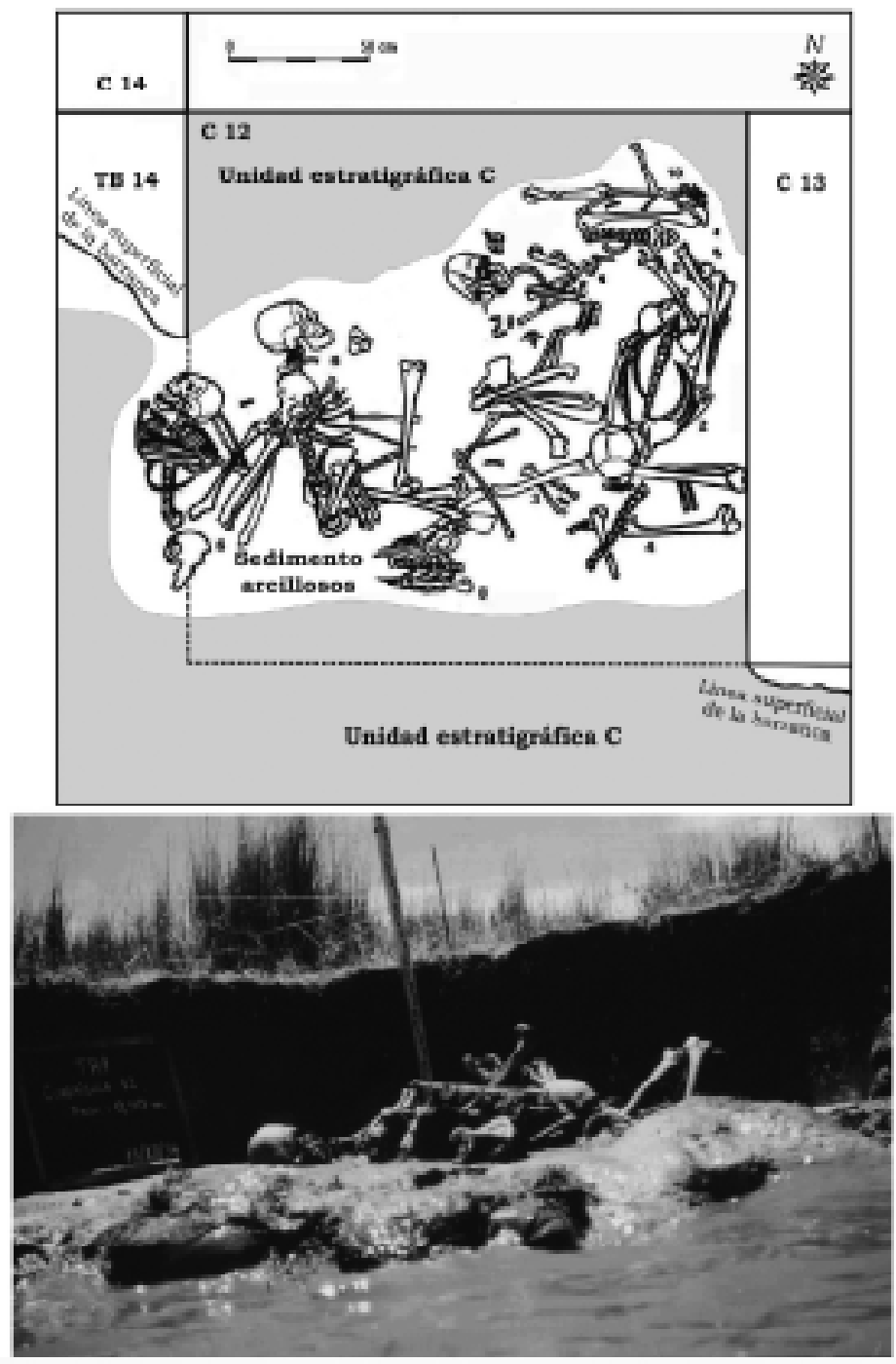

Figura 4. Disposición de los individuos en la cuadrícula 12 (Modificado a partir de Madrid y Barrientos 2000)

\begin{tabular}{|c|c|c|c|c|c|}
\hline Muestra & Taxín & $\begin{array}{c}\text { Unid ad } \\
\text { estratigráfica } \\
\end{array}$ & $\begin{array}{c}\text { Edad }{ }^{10} \mathrm{C} \\
\text { convencional }\end{array}$ & ${ }^{5}{ }^{13} \mathrm{C}$ & $\begin{array}{c}\text { Catib racion } \\
2 \sigma \\
\end{array}$ \\
\hline TR1.1 & Homo sapters & Sedimento entierro & $2.245 \pm 55 \mathrm{AP}$ & -172 & $2.350-2.120 \mathrm{AP}$ \\
\hline TR1 10 & Homo sapiens & Sedimento entierro & $2.470 \pm 60 \mathrm{AP}$ & -172 & $2.750-2.350 \mathrm{AP}$ \\
\hline $\operatorname{Tr} 1.6 . \mathrm{V} .29$ & $\begin{array}{l}\text { Lama } \\
\text { guaricos }\end{array}$ & A & $1.845+\$-50 \mathrm{AP}$ & -20.4 & $1.920-1.630 \mathrm{AP}$ \\
\hline TR16.V120 & $\begin{array}{l}\text { Lama } \\
\text { guavicoe }\end{array}$ & A & $2.280+/ .60 \mathrm{AP}$ & -19.4 & $2.360-2.130 \mathrm{AP}$ \\
\hline TR1.10X1.2 & $\begin{array}{l}\text { Lama } \\
\text { guaricas }\end{array}$ & B (parte apperion) & $2.235+/-50 \mathrm{AP}$ & -199 & $2.350-2120 \mathrm{AP}$ \\
\hline
\end{tabular}

Tabla 1. Fechados radiocarbónicos de TR1 (Modificado a partir de Madrid y Barrientos 2000) 
El material óseo que compone la muestra analizada fue extraído en el campo con un procedimiento similar al empleado en una situación de rescate arqueológico debido a la exposición de algunos huesos sobre la barranca y al avance del agua de la laguna sobre los mismos. Por razones analíticas y metodológicas, durante esta investigación, el conjunto de huesos que conforma los entierros de TR1 fue dividido en dos grupos teniendo en cuenta los datos de concentración espacial de las piezas óseas y las circunstancias particulares de extracción durante los trabajos de campo. El primero de ellos, el Grupo Individuos (GI), incluye los huesos que han podido ser asignados a su sistema esqueletal correspondiente ("individuo") por su situación espacial en el depósito sedimentario'. El segundo (Grupo Disociado: GD), reúne a los huesos que conforman un conjunto heterogéneo y que, al momento de la excavación, no poseían relaciones anatómicas establecidas con los esqueletos articulados del GI. Para algunos huesos correspondientes al GD se poseen medidas de ubicación espacial tridimensionales tomadas en el momento de la excavación, las cuales fueron utilizadas para el control de los desplazamientos horizontales/ verticales y para completar, siempre que fue posible, las asignaciones a nivel individual.

La mayor parte de las unidades óseas del conjunto de esqueletos GI se encontraban en su posición anatómica correspondiente. Los leves desplazamientos ocurridos entre los elementos óseos no impidieron la determinación de su pertenencia al sistema esqueletal correspondiente. Por consiguiente, cada uno de estos esqueletos fue considerado un subgrupo de huesos conformando elGI.

La muestra analizada está conformada por un NISP de 796 restos óseos humanos. De este total de huesos humanos, 708 elementos fueron identificados anatómicamente (MNE), de los cuales 518 corresponden al GI y 190 al GD. Los fragmentos anatómicamente indeterminados $(\mathrm{NISP}=88)$ no se consideraron al momento de establecer los resultados.

Como parte de la evaluación de este conjunto de entierros se realizaron análisis cuantitativos con el fin de obtener valores útiles para examinar la integridad anatómica del conjunto de entierros y los porcentuales de supervivencia relativa de cada unidad ósea. Estos índices contribuyen a conformar un cuerpo de información útil para construir la trayectoria tafonómica de los restos óseos humanos del sitio TR1.

En primera instancia, se calcularon las medidas cuantitativas básicas para un conjunto óseo, es decir MNE, NISP, MNI, MAU y MAU\% (Klein y Cruz-Uribe 1984; Lyman 1994; Reitz y Wing 1999). Además, se calcularon medidas cuantitativas por Individuo representado en la muestra. Así, se contabilizó el número de unidades óseas presentes por individuo para luego calcular la proporción entre el número de huesos representados y el número de huesos esperados en un esqueleto humano adulto completo 2 . Esta relación se expresó en porcentajes. En este caso, se toma como hueso presente cuando éste esta íntegro o cuando hay un fragmento/s del mismo que posibilita su identificación anatómica (presente ${ }^{1}$ entero). Los fragmentos que no pudieron ser asignados a una unidad ósea determinada no se contabilizaron para estas medidas. 


\section{Resultados}

Elementos óseos representados -GI.

En relación con la integridad esqueletal de los 9 individuos representados en este grupo, se observa que de 6 adultos, sólo uno (TR1-2) con 63,1\% de los huesos, entra en el rango porcentual 51-100\%, 4 de ellos (TR1-4, TR1-6, TR1-8 y TR1-10) caen en el rango 26-50\% en cuanto a las partes representadas y sólo TR1-1 presenta hasta un 25\% de sus unidades óseas. En cuanto a los individuos subadultos, sólo TR1-9 posee un porcentaje de huesos mayor al $25 \%(32,2 \%)$, el resto se ubica en el rango porcentual $0-25 \%$ respecto de las partes esqueletarias representadas. TR1-3 posee un 2,3\% y TR1-5 un 2,8\%. (Figura 5).

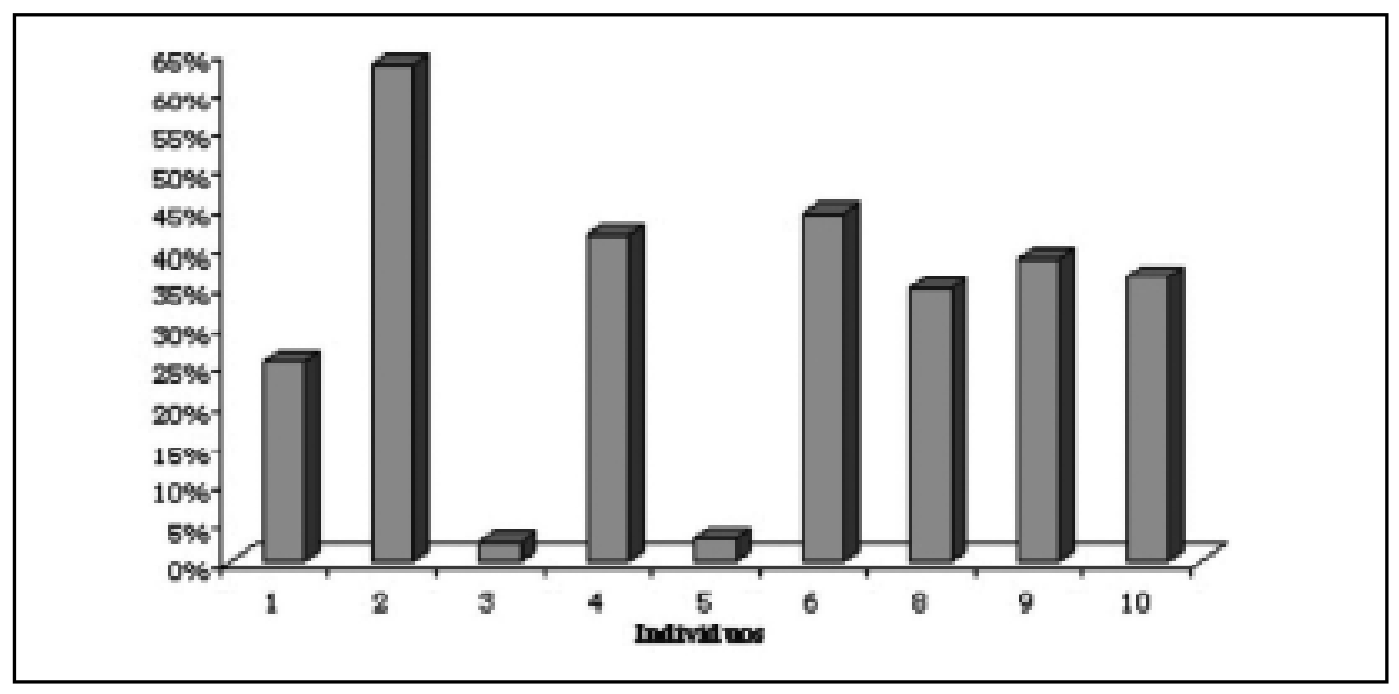

Figura 5. Porcentaje de elementos óseos recuperados por individuo en el GI.

Los elementos óseos con menor porcentaje de representación en el total del GI, sin discriminar categorías de edad, son aquellos de los pies y las manos, junto con el coxis y el hioides (Figura 6). Por otro lado, se estableció la relación entre huesos esperados y huesos hallados para cada elemento óseo teniendo en cuenta un NMI de 6 para los individuos adultos y un NMI de 3 para los juveniles (\% supervivencia). Para los adultos, los resultados obtenidos revelan que hioides, coxis, tarsos, metatarsos y falanges de las extremidades superiores e inferiores están presentes en valores menores al 30\% y al 35\%, específicamente, en el caso de los carpos y el atlas. Considerando la misma relación, le siguen en orden ascendente los huesos cuyo porcentaje de representación oscila entre el $40 \%$ y el $70 \%$. Los mismos corresponden a axis, vértebras cervicales, toráxicas, lumbares, esternón, clavícula y rótula. Por encima del $70 \%$ se hallan los cráneos y mandíbulas, sacro, costillas, escápulas, coxales y huesos largos de los miembros superiores e inferiores. Finalmente, las unidades anatómicas con una representación del 100\% son el fémur y el húmero (Figura 7). Para el caso de los individuos subadultos (NMI3), los análisis muestran que carpos, metacarpos y falanges proximales de la mano están representados por debajo de un $5 \%$. La rótula es el único elemento con una representación porcentual de entre un $10 \%$ a un $25 \%$. Por otro lado, 


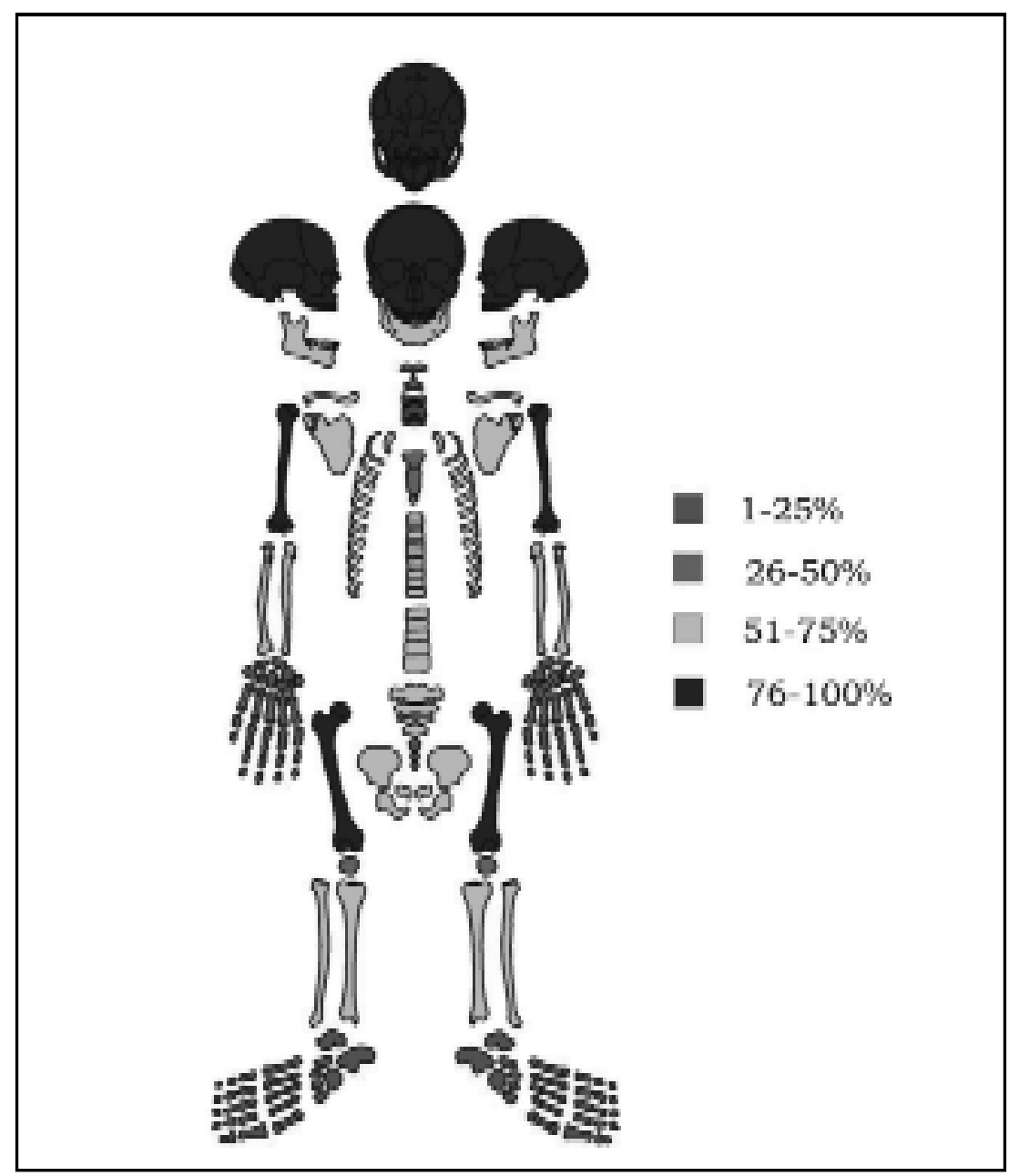

Figura 6. Índice de Supervivencia (\%Sup.) del GI.

en el rango 25-50\% se ubican la mayor parte de las unidades anatómicas presentes. Sólo el cráneo supera estos valores mostrando un índice de supervivencia del 66,7\% (Figura 7).

A escala individual se han calculado los valores de NMI, NME, MAU y MAU\%, los cuales son presentados en las tablas correspondientes a cada individuo ${ }^{3}$ (Tablas 2 a 10) con cada unidad anatómica identificada por lateralidad y por estado de fusión. A partir del análisis de las tablas surgen los siguientes resultados cuantitativos"

Individuo 1: posee un NME de 45, con un 25,1\% de unidades óseas respecto de un esqueleto adulto completo. El esqueleto axial se encuentra pobremente representado, si bien el cráneo se presenta entero. Los miembros están representados mayormente por los huesos largos, con la presencia casi nula de los elementos óseos que conforman manos y pies. En cuanto a las cinturas, la escapular sólo muestra un elemento, mientras que la pélvica exhibe la mayor parte de sus componentes (Tabla 2). 


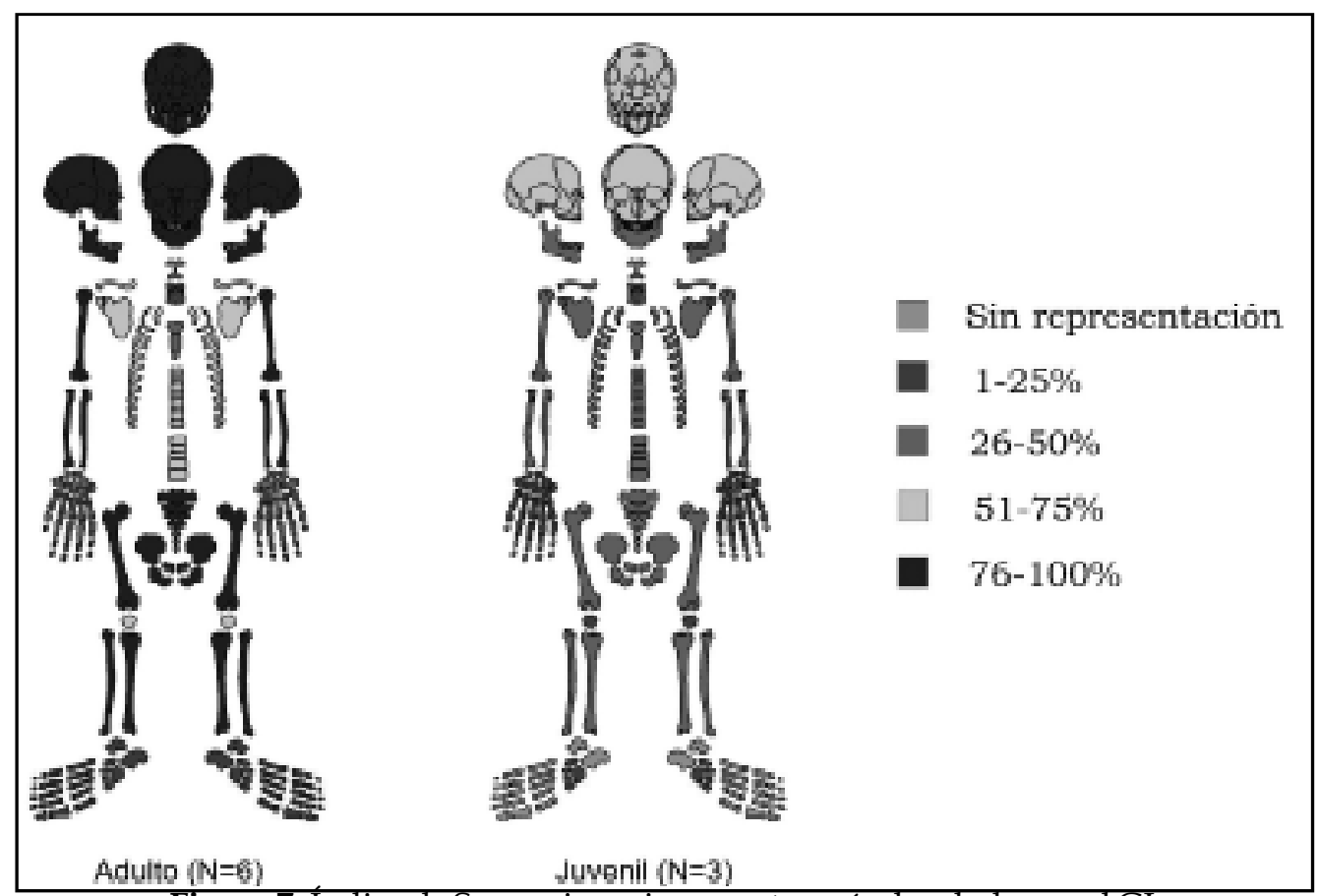

Figura 7. Índice de Supervivencia por categoría de edad para el GI.

Individuo 2: es el esqueleto con mayor representación de piezas óseas. Posee un NME de113, conformando un $63,1 \%$ del total esperado en un esqueleto adulto completo. El esqueleto axial se encuentra altamente representado. Los miembros superiores presentan casi la totalidad de sus elementos, mientras que en los inferiores los pies sólo cuentan con una unidad ósea. Ambas cinturas esqueletarias manifiestan un elevado porcentaje de representación (Tabla 3).

Individuo 3: posee un NME de 5, conformando un 2,3\% del total esperado. Presenta sólo el cráneo, sin la mandíbula, un hueso de la cintura escapular, uno de un miembro superior y dos elementos de un miembro inferior (Tabla 4).

Individuo 4: posee un NME de 74, lo que representa el 41,3\% del total esperado. A excepción de las manos, con un porcentaje mínimo de representatividad, las demás partes del esqueleto presentan aproximadamente la totalidad de los huesos que las constituyen (Tabla 5).

Individuo 5: su NME es de 6, con un 2,8\% de representatividad ósea. Presenta 4 huesos de los miembros inferiores y 2 de la mano (Tabla 6).

Individuo 6: con un 44,2\% de elementos óseos, presenta un NME de 79. El esqueleto axial se presenta casi en su totalidad. En cuanto a los miembros, nuevamente se ve que los huesos de pies y manos están subrepresentados, mientras que los huesos largos que los componen se encuentran altamente representados. La cintura escapular está completa mientras que la pélvica exhibe un único elemento (Tabla 7).

Individuo 8: su NME es de 62, implicando un 34,6\% del total esperado en un esqueleto completo. Las piezas óseas del esqueleto axial se presentan dentro de un rango porcentual medio, con ausencia de algunas vértebras.

Los miembros se hallan altamente representados por los huesos largos, con una abundancia mínima de los elementos óseos que integran los pies y las manos. Ambas cinturas muestran un elevado índice de representación, con la escapular mostrando todos sus elementos y la pélvica careciendo sólo del coxis (Tabla 8). 
Individuo 9: posee un NME de 69, conformando un 38,5\% del total esperado en un individuo adulto. El esqueleto axial y las cinturas escapular y pélvica presentan todas sus unidades anatómicas. Respecto de los miembros, los superiores presentan faltantes óseas en las manos, y los inferiores sólo exhiben ambos huesos de los muslos y uno de un pie (Tabla 9).

Individuo 10: posee un NME de 65. Su porcentaje de representación de piezas esqueletarias es del $36,3 \%$. Respecto del esqueleto axial, se destaca la ausencia del cráneo, de la mayoría de los huesos que componen la columna vertebral y de las costillas. Los miembros superiores exhiben un patrón similar a TR1-2 y diferente a la mayoría del conjunto ya que los huesos de las manos están presentes en aproximadamente un 50\%. Los huesos largos de los brazos poseen una alta representatividad, contrariamente a lo que sucede con los de los miembros inferiores donde sólo existen ambos fémures, un peroné y algunos elementos óseos de los pies. La cintura escapular está ausente mientras que la cintura pélvica ha perdido una de sus piezas óseas (Tabla 10).

Es notable que los 2 individuos con menor NME (TR1-3 y TR1-5) sean aquellos determinados como subadultos. A pesar de estas desigualdades en los números de piezas óseas representadas, la mayor parte de los individuos presentan una baja frecuencia de los huesos pertenecientes a manos y pies. Si se examina la relación entre la abundancia de elementos óseos y la edad de los individuos correspondientes, es visible una tendencia tomando en cuenta adultos y subadultos. Los individuos adultos de este grupo poseen una mayor representación de elementos óseos en relación con los subadultos (ver Figura 6).

\begin{tabular}{|c|c|c|c|c|c|c|c|c|c|c|c|c|}
\hline \multirow{2}{*}{ Unidad anat. } & \multicolumn{4}{|c|}{ Fus ionado } & \multicolumn{4}{|c|}{ Sin fusionar } & \multirow{2}{*}{ KMII } & \multirow{2}{*}{ TME } & \multirow{2}{*}{ MaU } & \multirow{2}{*}{$\% \mathrm{MAU}$} \\
\hline & I & D & $\mathbf{A}$ & Ind & I & D & $\mathbf{A}$ & Ind & & & & \\
\hline Cráneo & - & - & 1 & - & - & - & - & - & $\mathbf{1}$ & 1 & $\mathbf{1}$ & $100 \%$ \\
\hline Mand th ula & - & - & 1 & - & - & - & - & - & 1 & $\overline{1}$ & $\mathbf{1}$ & $100 \%$ \\
\hline Hioides & - & - & 1 & - & - & - & - & - & 1 & 1 & 1 & $100 \%$ \\
\hline Axis & - & - & 1 & - & - & - & - & - & $\mathbf{1}$ & $\mathbf{1}$ & $\mathbf{1}$ & $100 \%$ \\
\hline V. Cervical & - & - & 4 & - & - & - & - & - & 1 & 4 & 0,8 & $\mathbf{8 0 \%}$ \\
\hline V. Toráxica & - & - & 4 & - & - & - & - & - & 1 & 4 & 0,33 & $33 \%$ \\
\hline Sacro & - & - & 1 & - & - & - & - & - & 1 & 1 & 1 & $100 \%$ \\
\hline Costillas & 1 & 7 & - & 2 & - & - & - & - & $\overline{1}$ & 10 & 0,413 & $41,6 \%$ \\
\hline Clavíc ula & 1 & - & - & - & - & - & - & - & 1 & 1 & 0,5 & $50 \%$ \\
\hline Húmero & 1 & 1 & - & - & - & - & - & - & $\mathbf{1}$ & 2 & 1 & $100 \%$ \\
\hline Cúbito & 1 & 1 & - & - & - & - & - & - & 1 & 2 & 1 & $100 \%$ \\
\hline Fadio & - & 1 & - & - & - & - & - & - & $\overline{1}$ & $\mathbf{1}$ & 0,5 & $50 \%$ \\
\hline Falange px. & - & - & 2 & - & - & - & - & - & 1 & 2 & 0,2 & $20 \%$ \\
\hline Falange ds. & - & - & 2 & - & - & - & - & - & $\mathbf{1}$ & 2 & 0,2 & $20 \%$ \\
\hline Coxal & 1 & 1 & - & - & - & - & - & - & 1 & 2 & 1 & $100 \%$ \\
\hline Fémux & 1 & 1 & - & - & - & - & - & - & 1 & 2 & 1 & $100 \%$ \\
\hline Rótula & - & 1 & - & - & - & - & - & - & 1 & 1 & 0,5 & $50 \%$ \\
\hline Tibia & 1 & 1 & - & - & - & - & - & - & 1 & 2 & 1 & $100 \%$ \\
\hline Peroné & 1 & 1 & - & - & - & - & - & - & 1 & 2 & 1 & $100 \%$ \\
\hline Calcáneo & - & 1 & - & - & - & - & - & - & 1 & 1 & 0,5 & $\mathbf{5 0} \%$ \\
\hline Tarso & - & 1 & - & - & - & - & - & - & 1 & 1 & $\mathbf{0 , 1}$ & $10 \%$ \\
\hline Metatano & 1 & - & - & - & - & - & - & - & 1 & 1 & $\mathbf{0 , 1}$ & $10 \%$ \\
\hline & & & & & & & & & 1 & 45 & & \\
\hline
\end{tabular}

Tabla 2. Frecuencia de elementos óseos recuperados en TR1-1 (adulto). 


\begin{tabular}{|c|c|c|c|c|c|c|c|c|c|c|c|c|}
\hline \multirow{2}{*}{ Unidad anat. } & \multicolumn{4}{|c|}{ Fusionado } & \multicolumn{4}{|c|}{ Sin fusionar } & \multirow{2}{*}{ FM I } & \multirow{2}{*}{$\mathrm{SME}$} & \multirow[b]{2}{*}{ MคD } & \multirow{2}{*}{ \% M } \\
\hline & I & $\mathrm{D}$ & $A$ & Ind & I & D & $A$ & Ind & & & & \\
\hline Cráneo & - & - & 1 & - & - & - & - & - & 1 & 1 & 1 & $100 \%$ \\
\hline Mandibula & - & - & 1 & - & - & - & - & - & 1 & 1 & 1 & $100 \%$ \\
\hline Atles & - & - & 1 & - & - & - & - & - & 1 & 1 & 1 & $100 \%$ \\
\hline Axis & - & - & 1 & - & - & - & - & - & 1 & 1 & 1 & $100 \%$ \\
\hline v. Cervical & - & - & 5 & - & - & - & - & - & 1 & 5 & 1 & $100 \%$ \\
\hline V. Toráxica & - & - & 12 & - & - & - & - & - & 1 & 12 & 1 & $100 \%$ \\
\hline V. Lumbar & - & - & 5 & - & - & - & - & - & 1 & 5 & 1 & $100 \%$ \\
\hline Sacro & - & - & 1 & - & - & - & - & - & 1 & 1 & 1 & $100 \%$ \\
\hline Costilles & 11 & 12 & - & 1 & - & - & - & - & 1 & 24 & 1 & $100 \%$ \\
\hline Clavícula & 1 & 1 & - & - & - & - & - & - & 1 & 2 & 1 & $100 \%$ \\
\hline Escápula & 1 & 1 & - & - & - & - & - & - & 1 & 2 & 1 & $100 \%$ \\
\hline Húmero & 1 & 1 & - & - & - & - & - & - & 1 & 2 & 1 & $100 \%$ \\
\hline Cúbito & 1 & 1 & - & - & - & - & - & - & 1 & 2 & 1 & $100 \%$ \\
\hline Radio & 1 & 1 & - & - & - & - & - & - & 1 & 2 & 1 & $100 \%$ \\
\hline Carpo & 5 & 8 & - & - & - & - & - & - & 1 & 13 & 0,81 & $81 \%$ \\
\hline Metacapo & 5 & 5 & - & - & - & - & - & - & 1 & 10 & 1 & $100 \%$ \\
\hline Falange $p x$. & - & - & - & 9 & - & - & - & - & 1 & 9 & 0,9 & $90 \%$ \\
\hline Falange interm. & - & - & - & 5 & - & - & - & - & 1 & 5 & 0,625 & $62,5 \%$ \\
\hline Falange ds. & - & - & - & 3 & - & - & - & - & 1 & 3 & 0,3 & $30 \%$ \\
\hline Coocal & 1 & 1 & - & - & - & - & - & - & 1 & 2 & 1 & $100 \%$ \\
\hline Fémux & 1 & 1 & - & - & - & - & - & - & 1 & 2 & 1 & $100 \%$ \\
\hline Rótula & 1 & 1 & - & - & - & - & - & - & 1 & 2 & 1 & $100 \%$ \\
\hline Tibia & 1 & 1 & - & - & - & - & - & - & 1 & 2 & 1 & $100 \%$ \\
\hline Peroné & 1 & 1 & - & - & - & - & - & - & 1 & 2 & 1 & $100 \%$ \\
\hline Metatarso & - & - & - & 1 & - & - & - & - & 1 & 1 & 0,1 & $10 \%$ \\
\hline Falange interm. & - & - & - & 1 & - & - & - & - & 1 & 1 & 0,125 & $13 \%$ \\
\hline
\end{tabular}

Tabla 3. Frecuencia de elementos óseos recuperados en el individuo TR1-2 (adulto).

\begin{tabular}{|c|c|c|c|c|c|c|c|c|c|c|c|c|}
\hline \multirow{2}{*}{ Unidad anat. } & \multicolumn{4}{|c|}{ Fusionado } & \multicolumn{4}{|c|}{ Sin fusionar } & \multirow{2}{*}{ FM I } & \multirow{2}{*}{$\mathrm{FM} E$} & \multirow{2}{*}{ MAD } & \multirow{2}{*}{ W M } \\
\hline & I & $\mathrm{D}$ & $\mathrm{A}$ & Ind & $I$ & $\mathrm{D}$ & A & Ind & & & & \\
\hline Cráneo & - & - & 1 & - & - & - & - & - & 1 & 1 & 1 & $100 \%$ \\
\hline Escápula & - & 1 & - & - & - & - & - & - & 1 & 1 & 0,5 & $50 \%$ \\
\hline Húmero & - & 1 & - & - & - & - & - & - & 1 & 1 & 0,5 & $50 \%$ \\
\hline Tibia & - & 1 & - & - & - & - & - & - & 1 & 1 & 0,5 & $50 \%$ \\
\hline Peroné & - & 1 & - & - & - & - & - & - & 1 & 1 & 0,5 & $50 \%$ \\
\hline
\end{tabular}

Tabla 4. Frecuencia de elementos óseos recuperados en el individuo TR1-3 (juvenil). 


\begin{tabular}{|c|c|c|c|c|c|c|c|c|c|c|c|c|}
\hline \multirow{2}{*}{ Unidad anat. } & \multicolumn{4}{|c|}{ Fnsionado } & \multicolumn{4}{|c|}{ Sin fusionar } & \multirow{2}{*}{ FMI } & \multirow{2}{*}{ FME } & \multirow{2}{*}{$M A D$} & \multirow{2}{*}{ \% MO } \\
\hline & I & $\mathrm{D}$ & $\mathrm{A}$ & Ind & $\mathrm{I}$ & $\mathrm{D}$ & $A$ & Ind & & & & \\
\hline Cráneo & - & - & 1 & - & - & - & - & - & 1 & 1 & 1 & $100 \%$ \\
\hline Mandibula & - & - & 1 & - & - & - & - & - & 1 & 1 & 1 & $100 \%$ \\
\hline V. Cervical & - & - & 1 & - & - & - & - & - & 1 & 1 & 0,2 & $20 \%$ \\
\hline V. Toráxica & - & - & 9 & - & - & - & - & - & 1 & 9 & 0,75 & $75 \%$ \\
\hline V. Lumbar & - & - & 4 & - & - & - & - & - & 1 & 4 & 0,8 & $80 \%$ \\
\hline Sacro & - & - & 1 & - & - & - & - & - & 1 & 1 & 1 & $100 \%$ \\
\hline Estermón & - & - & 1 & - & - & - & - & - & 1 & 1 & 1 & $100 \%$ \\
\hline Costilles & 8 & 5 & - & - & - & - & - & - & 1 & 13 & 0,54 & $54 \%$ \\
\hline Clavícula & - & 1 & - & - & - & - & - & - & 1 & 1 & 0,5 & $50 \%$ \\
\hline Escápula & 1 & 1 & - & - & - & - & - & - & 1 & 2 & 1 & $100 \%$ \\
\hline Húmero & 1 & 1 & - & - & - & - & - & - & 1 & 2 & 1 & $100 \%$ \\
\hline Cúbito & 1 & 1 & - & - & - & - & - & - & 1 & 2 & 1 & $100 \%$ \\
\hline Radio & 1 & 1 & - & - & - & - & - & - & 1 & 2 & 1 & $100 \%$ \\
\hline Metacamo & 1 & - & - & - & - & - & - & - & 1 & 1 & 0,1 & $10 \%$ \\
\hline Falange interm. & - & - & - & 1 & - & - & - & - & 1 & 1 & 0,125 & $12,5 \%$ \\
\hline Coxal & 1 & 1 & - & - & - & - & - & - & 1 & 2 & 1 & $100 \%$ \\
\hline Fémux & 1 & 1 & - & - & - & - & - & - & 1 & 2 & 1 & $100 \%$ \\
\hline Rótula & 1 & - & - & - & - & - & - & - & 1 & 1 & 0,5 & $50 \%$ \\
\hline Tibia & 1 & 1 & - & - & - & - & - & - & 1 & 2 & 1 & $100 \%$ \\
\hline Peroné & 1 & 1 & - & - & - & - & - & - & 1 & 2 & 1 & $100 \%$ \\
\hline Astrágalo & 1 & 1 & - & - & - & - & - & - & 1 & 2 & 1 & $100 \%$ \\
\hline Calcáneo & 1 & 1 & - & - & - & - & - & - & 1 & 2 & 1 & $100 \%$ \\
\hline Tarso & 4 & 3 & - & - & - & - & - & - & 1 & 7 & 0,7 & $70 \%$ \\
\hline Metatarso & 4 & 2 & - & - & - & - & - & - & 1 & 6 & 0,6 & $60 \%$ \\
\hline Falare $p x$. & - & - & - & 5 & - & - & - & - & 1 & 5 & 0,5 & $50 \%$ \\
\hline Falange interm. & - & - & - & 1 & - & - & - & - & 1 & 1 & 0,125 & $12,5 \%$ \\
\hline & & & & & & & & & 1 & 74 & & \\
\hline
\end{tabular}

Tabla 5. Frecuencia de elementos óseos recuperados en el individuo TR1-4 (adulto).

\begin{tabular}{|c|c|c|c|c|c|c|c|c|c|c|c|c|}
\hline \multirow{2}{*}{ Unidad anat. } & \multicolumn{4}{|c|}{ Fusionado } & \multicolumn{4}{|c|}{ Sin fusionar } & \multirow{2}{*}{ FMI } & \multirow{2}{*}{ FME } & \multirow{2}{*}{ MAD } & \multirow{2}{*}{ \% M } \\
\hline & $I$ & D & $A$ & Ind & I & $\mathrm{D}$ & $A$ & Ind & & & & \\
\hline Metacarpo & - & - & - & 1 & - & - & - & - & 1 & 1 & 0,1 & $10 \%$ \\
\hline Falare $p x$.(mano) & - & - & - & 1 & - & - & - & - & 1 & 1 & 0,1 & $10 \%$ \\
\hline Tilo ia & 1 & 1 & - & - & - & - & - & - & 1 & 2 & 1 & $100 \%$ \\
\hline Peroné & 1 & 1 & - & - & - & - & - & - & 1 & 2 & 1 & $100 \%$ \\
\hline & & & & & & & & & 1 & 6 & & \\
\hline
\end{tabular}

Tabla 6. Frecuencia de elementos óseos recuperados en el individuo TR1-5 (juvenil). 


\begin{tabular}{|c|c|c|c|c|c|c|c|c|c|c|c|c|}
\hline \multirow{2}{*}{ Unidad anat. } & \multicolumn{4}{|c|}{ Fusionado } & \multicolumn{4}{|c|}{ Sin fusionar } & \multirow{2}{*}{$\mathrm{FMI}$} & \multirow{2}{*}{$\sin x$} & \multirow{2}{*}{ MaD } & \multirow{2}{*}{ \% MAU } \\
\hline & $I$ & D & $\mathrm{A}$ & Ind & I & D & $\mathrm{A}$ & Ind & & & & \\
\hline Cráneo & - & - & 1 & - & - & - & - & - & 1 & 1 & 1 & $100 \%$ \\
\hline Mandibula & - & - & 1 & - & - & - & - & - & 1 & 1 & 1 & $100 \%$ \\
\hline Atlas & - & - & 1 & - & - & - & - & - & 1 & 1 & 1 & $100 \%$ \\
\hline Axis & - & - & 1 & - & - & - & - & - & 1 & 1 & 1 & $100 \%$ \\
\hline V. Cervical & - & - & 5 & - & - & - & - & - & 1 & 5 & 1 & $100 \%$ \\
\hline v. Toráxica & - & - & 12 & - & - & - & - & - & 1 & 12 & 1 & $100 \%$ \\
\hline V. Lumbar & - & - & 4 & - & - & - & - & - & 1 & 4 & 0,8 & $80 \%$ \\
\hline Sacro & - & - & - & - & - & - & - & - & - & - & 1 & $100 \%$ \\
\hline Esterrón & - & - & 1 & - & - & - & - & - & 1 & 1 & 1 & $100 \%$ \\
\hline Costillas & 12 & 12 & - & - & - & - & - & - & 1 & 24 & 1 & $100 \%$ \\
\hline Clavicula & 1 & 1 & - & - & - & - & - & - & 1 & 2 & 1 & $100 \%$ \\
\hline Escápula & 1 & 1 & - & - & - & - & - & - & 1 & 2 & 1 & $100 \%$ \\
\hline Húmero & 1 & 1 & - & - & - & - & - & - & 1 & 2 & 1 & $100 \%$ \\
\hline Cúbito & 1 & - & - & - & - & - & - & - & 1 & 1 & 0,5 & $50 \%$ \\
\hline Radio & 1 & - & - & - & - & - & - & - & 1 & 1 & 0,5 & $50 \%$ \\
\hline Carpo & 6 & 1 & - & - & - & - & - & - & 1 & 7 & 0,437 & $43,7 \%$ \\
\hline Metacamo & 5 & - & - & - & - & - & - & - & 1 & 5 & 0,5 & $50 \%$ \\
\hline Coxal & 1 & - & - & - & - & - & - & - & 1 & 1 & 0,5 & $50 \%$ \\
\hline Fémur & 1 & 1 & - & - & - & - & - & - & 1 & 2 & 1 & $100 \%$ \\
\hline Rótula & 1 & - & - & - & - & - & - & - & 1 & 1 & 0,5 & $50 \%$ \\
\hline Tibia & 1 & 1 & - & - & - & - & - & - & 1 & 2 & 1 & $100 \%$ \\
\hline Peroné & 1 & 1 & - & - & - & - & - & - & 1 & 2 & 1 & $100 \%$ \\
\hline Metatarso & - & 1 & - & - & - & - & - & - & 1 & 1 & 0,1 & $10 \%$ \\
\hline & & & & & & & & & 1 & 79 & & \\
\hline
\end{tabular}

I apıa \%. rrecuencia ae eıementos oseos recuperaaos en el inaıviauo I Kı-b (aauıto).

\begin{tabular}{|c|c|c|c|c|c|c|c|c|c|c|c|c|}
\hline \multirow{2}{*}{ Unidad anat. } & \multicolumn{4}{|c|}{ Fnsionado } & \multicolumn{4}{|c|}{ Sin fusionar } & \multirow{2}{*}{ FMI I } & \multirow{2}{*}{$\sin E$} & \multirow{2}{*}{ Мяण } & \multirow{2}{*}{ \% MAD } \\
\hline & $I$ & D & A & Ind & I & D & $A$ & Ind & & & & \\
\hline Cráneo & - & - & 1 & - & - & - & - & - & 1 & 1 & 1 & $100 \%$ \\
\hline Mandibula & - & - & 1 & - & - & - & - & - & 1 & 1 & 1 & $100 \%$ \\
\hline v. Toráxica & - & - & 10 & - & - & - & - & - & 1 & 10 & 0,83 & $83 \%$ \\
\hline v. Lumbar & - & - & 1 & - & - & - & - & - & 1 & 1 & 0,2 & $20 \%$ \\
\hline Sacro & - & - & 1 & - & - & - & - & - & 1 & 1 & 1 & $100 \%$ \\
\hline Esternón & - & - & 1 & - & - & - & - & - & 1 & 1 & 1 & $100 \%$ \\
\hline Costillas & 11 & 12 & - & - & - & - & - & - & 1 & 23 & 0,958 & $95,8 \%$ \\
\hline Clavícula & 1 & 1 & - & - & - & - & - & - & 1 & 2 & 1 & $100 \%$ \\
\hline Escápula & 1 & 1 & - & - & - & - & - & - & 1 & 2 & 1 & $100 \%$ \\
\hline Húmero & 1 & 1 & - & - & - & - & - & - & 1 & 2 & 1 & $100 \%$ \\
\hline Cúbito & 1 & 1 & - & - & - & - & - & - & 1 & 2 & 1 & $100 \%$ \\
\hline Radio & 1 & 1 & - & - & - & - & - & - & 1 & 2 & 1 & $100 \%$ \\
\hline Carpo & - & 2 & - & - & - & - & - & - & 1 & 2 & 0,125 & $13 \%$ \\
\hline Metacapo & - & 2 & - & 1 & - & - & - & - & 1 & 3 & 0,3 & $30 \%$ \\
\hline Falarge $p x$ & - & - & - & 1 & - & - & - & - & 1 & 1 & 0,1 & $10 \%$ \\
\hline Coral & 1 & 1 & - & - & - & - & - & - & 1 & 2 & 1 & $100 \%$ \\
\hline Fémur & 1 & 1 & - & - & - & - & - & - & 1 & 2 & 1 & $100 \%$ \\
\hline Rótula & - & 1 & - & - & - & - & - & - & 1 & 1 & 0,5 & $50 \%$ \\
\hline Tibia & 1 & 1 & - & - & - & - & - & - & 1 & 2 & 1 & $100 \%$ \\
\hline Peroné & - & 1 & - & - & - & - & - & - & 1 & 1 & 0,5 & $50 \%$ \\
\hline & & & & & & & & & 1 & 62 & & \\
\hline
\end{tabular}

Tabla 8. Frecuencia de elementos óseos recuperados en el individuo TR1-8 (adulto). 


\begin{tabular}{|c|c|c|c|c|c|c|c|c|c|c|c|c|}
\hline \multirow{2}{*}{ Unidad anat. } & \multicolumn{4}{|c|}{ Fusionado } & \multicolumn{4}{|c|}{ Sin fusionar } & \multirow{2}{*}{$\mathrm{FM} \mathrm{I}$} & \multirow{2}{*}{$\mathrm{FM} \mathrm{E}$} & \multirow{2}{*}{ MAD } & \multirow{2}{*}{ \% MU } \\
\hline & I & D & A & Ind & I & D & $\mathrm{A}$ & Ind & & & & \\
\hline Cráneo & - & - & 1 & - & - & - & - & - & 1 & 1 & 1 & $100 \%$ \\
\hline Mandibula & - & - & 1 & - & - & - & - & - & 1 & 1 & 1 & $100 \%$ \\
\hline Atlas & - & - & 1 & - & - & - & - & - & 1 & 1 & 1 & $100 \%$ \\
\hline Axis & - & - & 1 & - & - & - & - & - & 1 & 1 & 1 & $100 \%$ \\
\hline v. Cervical & - & - & 5 & - & - & - & - & - & 1 & 5 & 1 & $100 \%$ \\
\hline v. Toráxica & - & - & 12 & - & - & - & - & - & 1 & 12 & 1 & $100 \%$ \\
\hline V. Lumbar & - & - & 5 & - & - & - & - & - & 1 & 5 & 1 & $100 \%$ \\
\hline Sacro & - & - & 1 & - & - & - & - & - & 1 & 1 & 1 & $100 \%$ \\
\hline Estermón & - & - & 1 & - & - & - & - & - & 1 & 1 & 1 & $100 \%$ \\
\hline Costillas & 12 & 12 & 24 & - & - & - & - & - & 1 & 24 & 1 & $100 \%$ \\
\hline Clavícula & 1 & 1 & - & - & - & - & - & - & 1 & 2 & 1 & $100 \%$ \\
\hline Escápula & 1 & 1 & - & - & - & - & - & - & 1 & 2 & 1 & $100 \%$ \\
\hline Húmero & 1 & 1 & - & - & - & - & - & - & 1 & 2 & 1 & $100 \%$ \\
\hline Cúbito & 1 & 1 & - & - & - & - & - & - & 1 & 2 & 1 & $100 \%$ \\
\hline Radio & 1 & 1 & - & - & - & - & - & - & 1 & 2 & 1 & $100 \%$ \\
\hline Carpo & - & 1 & - & - & - & - & - & - & 1 & 1 & 0,063 & $6 \%$ \\
\hline Coxal & 1 & 1 & - & & - & - & - & - & 1 & 2 & 1 & $100 \%$ \\
\hline Fémux & 1 & 1 & - & & - & - & - & - & 1 & 2 & 1 & $100 \%$ \\
\hline Rótula & 1 & - & - & - & - & - & - & - & 1 & 1 & 0,5 & $50 \%$ \\
\hline Tarso & - & 1 & - & - & - & - & - & - & 1 & 1 & 0,1 & $10 \%$ \\
\hline
\end{tabular}

Tabla 9. Frecuencia de elementos óseos recuperados en el individuo TR1-9 (juvenil).

\begin{tabular}{|c|c|c|c|c|c|c|c|c|c|c|c|c|}
\hline \multirow{2}{*}{ Unidad anat. } & \multicolumn{4}{|c|}{ Fusionado } & \multicolumn{4}{|c|}{ Sin fusionar } & \multirow{2}{*}{$\sin I$} & \multirow{2}{*}{$\sin \mathrm{E}$} & \multirow{2}{*}{ мяण } & \multirow{2}{*}{ \% MRU } \\
\hline & I & $\mathrm{D}$ & $\mathrm{A}$ & Ind & I & D & $\mathrm{A}$ & Ind & & & & \\
\hline V. Toráxica & - & - & 3 & - & - & - & - & - & 1 & 3 & 0,25 & $25 \%$ \\
\hline V. Lumbar & - & - & 5 & - & - & - & - & - & 1 & 5 & 1 & $100 \%$ \\
\hline Sacro & - & - & 1 & - & - & - & - & - & 1 & 1 & 1 & $100 \%$ \\
\hline Coxis & - & - & 1 & - & - & - & - & - & 1 & 1 & 1 & $100 \%$ \\
\hline Costillas & 2 & 1 & - & 10 & - & - & - & - & 1 & 13 & 0,54 & $54 \%$ \\
\hline Húmero & 1 & 1 & - & - & - & - & - & - & 1 & 2 & 1 & $100 \%$ \\
\hline Cúbito & 1 & - & - & - & - & - & - & - & 1 & 1 & 0,5 & $50 \%$ \\
\hline Radio & 1 & 1 & - & - & - & - & - & - & 1 & 2 & 1 & $100 \%$ \\
\hline Carpo & 6 & 3 & - & - & - & - & - & - & 1 & 9 & 0,56 & $56 \%$ \\
\hline Metacapo & 5 & 1 & - & - & - & - & - & - & 1 & 6 & 0,6 & $60 \%$ \\
\hline Falarge $p x$. & 5 & - & - & 1 & - & - & - & - & 1 & 6 & 0,6 & $60 \%$ \\
\hline Falange interm. & 4 & - & - & - & - & - & - & - & 1 & 4 & 0,5 & $50 \%$ \\
\hline Coxal & 1 & - & - & - & - & - & - & - & 1 & 1 & 0,5 & $50 \%$ \\
\hline Fémux & 1 & 1 & - & & - & - & - & - & 1 & 2 & 1 & $100 \%$ \\
\hline Rótula & 1 & - & - & - & - & - & - & - & 1 & 1 & 0,5 & $50 \%$ \\
\hline Peroné & 1 & - & - & - & - & - & - & - & 1 & 1 & 0,5 & $50 \%$ \\
\hline Astrágalo & - & 1 & - & - & - & - & - & - & 1 & 1 & 0,5 & $50 \%$ \\
\hline Tarso & - & 3 & - & 1 & - & - & - & - & 1 & 4 & 0,4 & $40 \%$ \\
\hline Falarge $p x$ & - & 1 & - & - & - & - & - & - & 1 & 1 & 0,1 & $10 \%$ \\
\hline Falange ds. & - & 1 & - & - & - & - & - & - & 1 & 1 & 0,1 & $10 \%$ \\
\hline & & & & & & & & & 1 & 65 & & \\
\hline
\end{tabular}

Tabla 10. Frecuencia de elementos óseos recuperados en el individuo TR1-10 (adulto). 
En este sentido, con el fin de investigar el grado de participación que la densidad mineral ósea ha tenido en la configuración final del registro biológico humano de TR1, se comparó el porcentual de supervivencia de los huesos largos del GI con los valores correspondientes de densidad mineral ósea por circunferencia (DMOc). Se tomaron las estimaciones obtenidas por Galloway et al. (1997) ya que hasta el momento resultan más aplicables, debido a que la metodología empleada está claramente detallada y por la inclusión de una serie de sitios de escaneo para cada hueso. Por otro lado, ha sido demostrado que en los conjuntos óseos humanos la DMOc está fuertemente correlacionada con la supervivencia del hueso y describe en forma más eficiente la densidad en relación con otras medidas, como la densidad mineral ósea (DMO) y la densidad de volumen (DV) (Willey et al. 1997). No obstante, se reconoce la ambigüedad que este tipo de comparaciones puede arrojar debido a las deficiencias propias de las técnicas de medición de DMO y debido a la amplia variedad de factores que influencian el contenido mineral en los huesos humanos en distintas poblaciones (ver comentarios en González 2006: 19). Para adecuar la información provista por Galloway et al. (1997: Tablas 2 y 3) a los datos de la muestra de TR1, fue necesario cierto procesamiento de tales datos (ver González 2006). La relación entre estas dos variables fue testeada por el análisis de correlación deSpearman. Los resultados de la correlación ( $r$ ho de Spearman) entre la frecuencia relativa de los huesos largos de esta muestra y los valores de densidad mineral ósea, indican que no existe una correlación significativa $(\mathrm{p}>0,05)$ entre estas dos variables (Figura 8 )

Respecto a las ubicaciones de los esqueletos en el espacio delimitado por la cuadrícula de excavación $(2 \mathrm{~m} \times 2 \mathrm{~m})$ y su correlación con la abundancia de elementos óseos por individuo, es posible establecer que la misma no coincide con lo esperado si se considera a la acción hídrica de la laguna como un factor causal de la pérdida ósea en determinados esqueletos. De este modo, aquellos individuos localizados hacia el sector de la barranca de la laguna (TR1-6, TR1-9 y TR1-8) con el espejo de agua ya avanzando sobre ellos, conforman sistemas esqueletarios bien representados (ver Figura 4). Contrariamente, los situados hacia el sector centro y norte de la cuadrícula parecen exhibir más perturbaciones en sus disposiciones anatómicas y espaciales (TR1-1, TR1-3 y TR1-10).

Según se distingue en la figura de la planta de excavaciones (Figura 3), en un periodo de 10 años la línea de barranca ha retrocedido en forma irregular hasta un máximo de $10 \mathrm{~m}$ en distintos sectores. Esta situación manifiesta la posibilidad de que los entierros de TR1 hayan sido inhumados originalmente a una distancia considerable de la costa de la laguna,

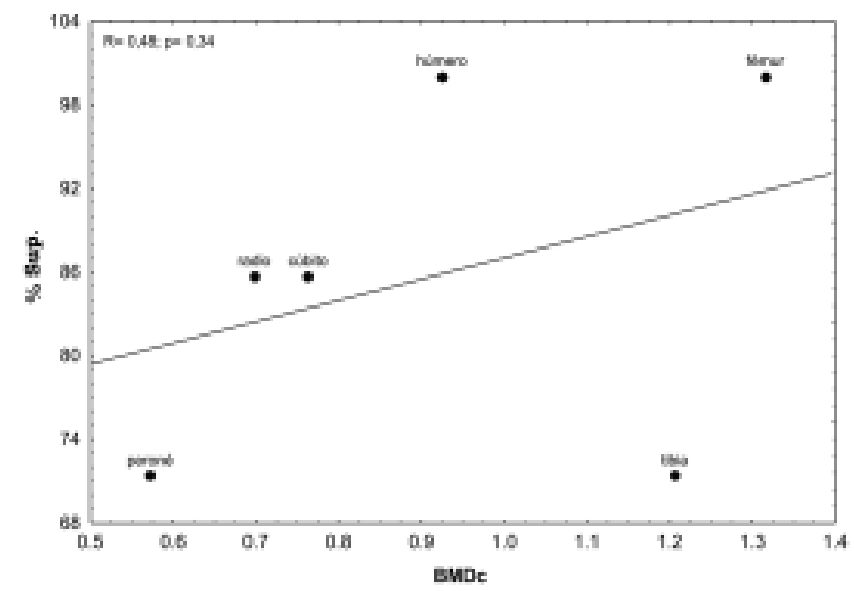

Figura 8. Gráfico de dispersión entre \% deSup. y valores de DMOc para el Grupo Individuos (GI). 
culminando en la situación actual en la que fueron hallados debido a la dinámica de este cuerpo de agua. Si bien el accionar de la laguna pudo haber influenciado en la estructuración actual de los esqueletos y en la disposición de los elementos óseos esto debió suceder en los últimos años y en forma exigua, aunque podría ser uno de los factores que provocó la exposición en la barranca de algunos huesos. Por consiguiente, con un estudio de la dinámica ambiental local podrían establecerse características que contribuyan a la comprensión de este aspecto particular.

\section{Elementos óseos representados -GD.}

En este trabajo, el cúbito infantil que representa al denominado TR1-7 (Barrientos 1997; Madrid y Barrientos 2000), es considerado dentro del GD dado que posee las características que lo definen (fue hallado en forma aislada, sin correspondencias anatómicas con un esqueleto y desplazado respecto del conjunto GI). Su inclusión en este grupo no invalida su determinación como un individuo diferente de los 9 restantes ya que así lo permiten sus características morfológicas, sus dimensiones y su grado de desarrollo ontogénico.

Para este grupo de huesos se calcularon los mismos índices que para el Grupo Individuos, con la excepción de que aquí al momento de estimar la abundancia de elementos óseos para todo el grupo se calculó su MAU\% (Tabla 11). En el GD los elementos con el MAU\% más elevado $(100 \%)$ son los astrágalos y, dentro de esta tendencia, se observa que la lateralidad más representada es la izquierda. Así, estos arrojan un NMI de 5 para todo el conjunto. En orden descendente, en el siguiente rango porcentual (51-75\%), se encuentran exclusivamente las falanges intermedias de las manos, las cuales muestran una frecuencia casi equiparable entre los elementos con fusión completa y aquellos sin fusionar o semifusionados. Los demás huesos de la mano, junto con los huesos del tarso, los cúbitos representados y los fragmentos de 2 cráneos (uno fusionado y otro sin fusionar), conforman el rango entre $26 \%$ y $50 \%$. Las piezas esqueletarias con menor abundancia relativa en este grupo son los restantes huesos del pie, los elementos del esqueleto axial (exceptuando cráneo y axis), los que componen la cintura escapular, los restantes huesos largos de los miembros superiores y ciertas unidades óseas de los miembros inferiores, aunque la gran mayoría de estas están ausentes (Figura 9)..

A partir de estos resultados cuantitativos es posible concluir que en este grupo no se hallaron datos para establecer la existencia de uno o varios individuos más de los ya determinados para la muestra aquí analizada (Barrientos 1997). En este sentido, los astrágalos, presentando el MAU\% más elevado no alcanzan a cubrir las faltantes de los mismos en el GI. Además, respecto de la lateralidad más representada en el GD (izquierda), ésta indica la existencia de 5 individuos mientras que en el GI los individuos con ausencia de ambos astrágalos son 8 .

En cuanto a los esqueletos adultos y subadultos, la información cuantitativa obtenida en este grupo no altera las estimaciones determinadas para toda la muestra. Uno de los fragmentos de cráneo que aparecen en este conjunto tiene características de un individuo subadulto y podría corresponder a TR1-3 o a TR1-7. No pudieron realizarse análisis osteométricos, ya que la parte craneal presente no poseía las condiciones de integridad para tales mediciones. Por otro lado, puede estimarse que dicho fragmento pertenece a un individuo subadulto ya que las porciones frontal y malar presentes permiten ver rasgos asociados a las clases de edad denominadas infancia y niñez (Buikstra y Ubelaker 1994). 


\begin{tabular}{|c|c|c|c|c|c|c|c|c|c|c|c|c|}
\hline \multirow{2}{*}{ Unidad anat. } & \multicolumn{4}{|c|}{ Fusionado } & \multicolumn{4}{|c|}{ Sin fusionar } & \multirow{2}{*}{ NMI } & \multirow[b]{2}{*}{ NME } & \multirow{2}{*}{ MAU } & \multirow{2}{*}{$\%$ MAU } \\
\hline & I & D & A & Indet. & III & D & & Indet. & & & & \\
\hline Cráneo & - & - & 1 & - & -1. & - & 1 & - & $\overline{2}$ & 2 & 2 & $50 \%$ \\
\hline Hioides & - & - & 1 & - &.- & - & 1 & - & 2 & 2 & 2 & $50 \%$ \\
\hline Atlas & - & - & 1 & - & . & - & -1 & - & 1 & 1 & 1 & $25 \%$ \\
\hline Axis & - & - & 2 & - &. & -1 & -1 & - & 2 & 2 & 2 & $50 \%$ \\
\hline V.Cervical & - & - & 4 & - &. & - & - & - & 1 & 4 & 0,8 & $20 \%$ \\
\hline V. Toráxica & - & - & 6 & - & . & -1 & 1 & - & 1 & 7 & 0,58 & $14,5 \%$ \\
\hline V. Lumbar & - & - & 4 & 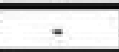 & -1. & -1 & 1 & - & 1 & 5 & 1 & $25 \%$ \\
\hline V. Sacrales & - & - & - & - & -1. & -1 & 3 & - & 1 & 3 & 0,6 & $15 \%$ \\
\hline V. Indet. & - & - & 2 & - &.- & -1 & -1 & - & 1 & 2 & $0,08 *$ & $2,0 \%$ \\
\hline Sacro & - & - & - & - & -1. & -1 & 1 & - & 1 & 1 & 1 & $25 \%$ \\
\hline Cóccis & - & - & - & - & -1. & -1 & 1 & - & 1 & 1 & 1 & $25 \%$ \\
\hline Estemón & - & - & 1 & - & .. & -1 & 1 & - & 2 & 2 & 1 & $25 \%$ \\
\hline Costillas. Ext. Est. & 2 & 1 & - & - & 1. & - & -1 & - & 1 & 3 & 0,12 & $3 \%$ \\
\hline Costillas. Ext. Vert. & 3 & 2 & - & - & . & - & - & 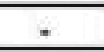 & 1 & 5 & 0,2 & $5 \%$ \\
\hline Costill as indet. &. & . & - & 6 & .. & $=$ & - & 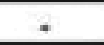 & 1 & 6 & $0,25 *$ & $6,25 \%$ \\
\hline Clavícula & - & - & - & 1 & . & - & - & - & 1 & 1 & 1 & $25 \%$ \\
\hline Escápula & - & 1 & - & 1 & -1. & - & -1 & - & 1 & 2 & 1 & $25 \%$ \\
\hline Húmero medio & - & - & - & - & 1. & - & - & - & 1 & 1 & 0,5 & $12,5 \%$ \\
\hline Húmero ds. & - & - & - & - & 1. & - & - & - & 1 & 1 & 0,5 & $12,5 \%$ \\
\hline Cúbito px. & - & - & - & - & 12 & $2 \mid$ & -1 & - & 2 & 3 & 1,5 & $37,5 \%$ \\
\hline Cúbito medio & - & - & - & - & 122 & 2 & -1 & - & 2 & 3 & 1,5 & $37,5 \%$ \\
\hline Cúbito ds. & - & - & - & $=$ & & 2 & -1 & - & 2 & 3 & 1,5 & $37,5 \%$ \\
\hline Radio px. & - & - & - & $=$ & 1 . & .1 & -1 & - & 1 & 1 & 0,5 & $12,5 \%$ \\
\hline Radio medio & - & . & - & - & 1. & - & -1 & - & 1 & 1 & 0,5 & $12,5 \%$ \\
\hline Radio ds. & 1 & . & -1 & - & . & - & -1 & - & 1 & 1 & 0,5 & $12,5 \%$ \\
\hline Carpo & 11 & 7 & - & - & -1. & -1 & -1 & - & 2 & 18 & 1,12 & $28 \%$ \\
\hline Metacarpo & 2 & -1 & -1 & 6 & $2 \sqrt{2}$ & \begin{tabular}{l|l}
4 & -1
\end{tabular} & -1 & 2 & 2 & 16 & 1,6 & $40 \%$ \\
\hline Falange px. & - & - & -1 & 10 & -1. & -7 & - & $\frac{T}{1}$ & $\overline{2}$ & $\overline{11}$ & 1,1 & $27,5 \%$ \\
\hline Fal ange interm. & - & - & -1 & $\overline{9}$ & .1. & - & -7 & 11 & $\overline{4}$ & 20 & 2,5 & $62,5 \%$ \\
\hline Falange ds. & - & - & - & 3 & . & - & -1 & 10 & 2 & 13 & 1,3 & $32,5 \%$ \\
\hline Rótula &. & 2 & -1 & 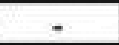 & 1. & - & -1 & , & 2 & 2 & 1 & $25 \%$ \\
\hline Peroné ds. &. & . & - & 1 & .1. & - &. & $\bar{F}$ & 1 & 1 & 0,5 & $12,5 \%$ \\
\hline Astrágalo & 5 & 2 & - & 1 & .1. & - & -1 & - & 5 & 8 & 4 & $100 \%$ \\
\hline Calcáneo & 2 & 1 & - & 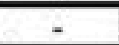 & . &. & -1 & $=$ & $\overline{2}$ & 3 & 1,5 & $37,5 \%$ \\
\hline Tarso & 7 & 6 & - & 1 & .1. & - & -1 & $\bar{z}$ & 2 & 14 & 1,4 & $35 \%$ \\
\hline Metatarso & 4 & 4 & - & 2 & 1. & - & - & - & 1 & 10 & 1 & $25 \%$ \\
\hline Falange px. & - & - & - & 6 & -1. & - & - & - & 1 & 6 & 0,6 & $15 \%$ \\
\hline Fal ange interm. & - & - & - & 3 & .1. & - & - & 1 & 1 & 4 & 0,5 & $12,5 \%$ \\
\hline Falange ds. & - & - & -1 & 3 & 1. & - & - & - & 1 & 3 & 0,3 & $7,5 \%$ \\
\hline & & & & & & & & & 5 & 189 & & \\
\hline
\end{tabular}

Tabla 11. Frecuencia de elementos óseos recuperados (GD). 


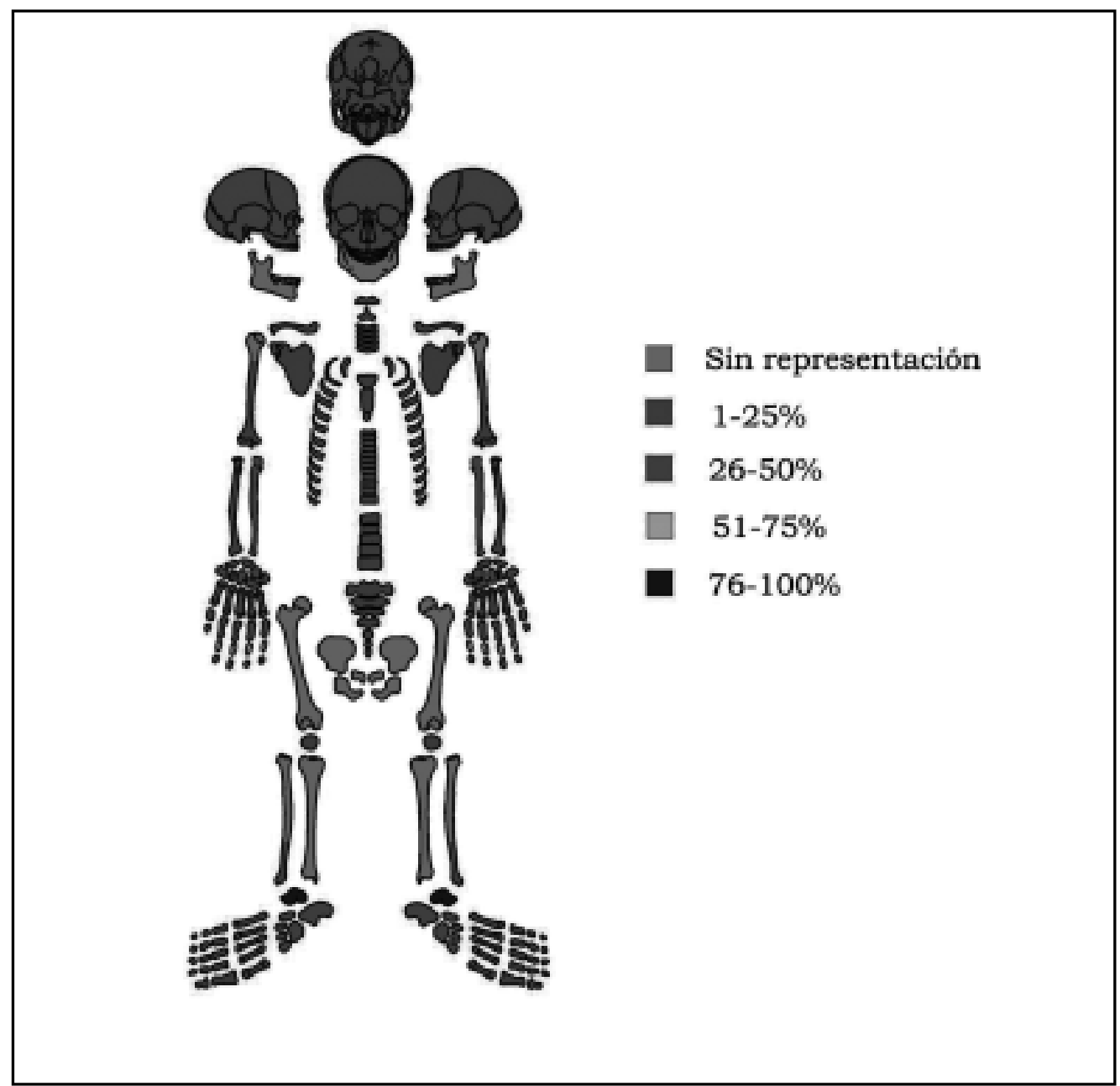

Figura 9. MAU\% de los elementos óseos del GD con datos de profundidad .

Al comparar los huesos presentes en cada grupo, se puede notar una "compensación" de las faltantes izquierdas de los huesos del pie en el GI con la presencia mayoritaria de esa misma lateralidad y tipo de elementos para el GD. Para el caso de los carpos y metacarpos es posible establecer una relación de este tipo; es decir, el GI manifiesta una baja representación de estos elementos mientras que los mismos son los de mayor abundancia en el GD. Lo mismo sucede para otras unidades esqueletarias en menores abundancias. De este modo, es clara la correspondencia entre ambos grupos de huesos como partes de un todo que fue dividido por cuestiones de concentración espacial y circunstanciales durante los trabajos de campo y por razones analíticas y metodológicas en este trabajo. Por consiguiente, los elementos óseos del GD complementan algunas de las ausencias esqueletarias del GI y ponen de manifiesto la acción perturbadora de procesos tafonómicos que han llevado a su desplazamiento y, por lo tanto, a alterar su integridad anatómica y estructural como conjunto de esqueletos articulados. Por otro lado, a partir de los resultados del análisis cuantitativo es viable postular la inexistencia de nuevo/s individuo/s en el GD, corroborando el NMI (10) obtenido para esta muestra biológica. Esta conclusión es destacable ya que esta serie de 
unidades anatómicas no había sido analizada detalladamente hasta el momento, dejando abierta la posibilidad de que más esqueletos estuviesen representados en el registro bioarqueológico de TR1.

Como tendencia en el aspecto anatómico del GD, los resultados revelan que los huesos con mayor frecuencia de representación son aquellos que corresponden a manos y pies. Es de destacar que los elementos pertenecientes a los miembros superiores corresponden a individuos subadultos, inclusive se los puede clasificar dentro de la clase de edad niñez y un elemento a la clase infancia (sensu Buikstra y Ubelaker 1994), y el otro hueso largo representado es un fragmento distal de peroné. Estas características óseas hacen evidente una de las propiedades que identifica a todo el conjunto (GD): el tamaño pequeño de la gran mayoría de sus componentes. Asimismo, otra de las peculiaridades del GD se relaciona con la presencia de partes esqueletarias de bajo contenido mineral (Galloway et al 1997; Suby y Guichón 2004).

Análisis distribucional de los elementos óseos del GD

En este análisis se buscó correlacionar los huesos correspondientes al denominado GD con los esqueletos del GI. Por medio del reconocimiento de los elementos óseos faltantes en los individuos y los representados en el GD con medidas de ubicación espacial tridimensional, se procedió a la búsqueda de correspondencias anatómicas. La metodología utilizada fue la superposición de mapeos y el análisis de las distribuciones espaciales de las piezas óseas. Como primer paso, se trazó el mapeo de los huesos del GD que poseían mediciones de ubicación espacial (en este caso sólo se utilizaron las bidimensionales), para establecer desplazamientos horizontales. Luego, el mapeo resultante, con la identificación de los huesos, fue superpuesto al mapeo de planta de los individuos (o esqueletos) de la cuadrícula 12.

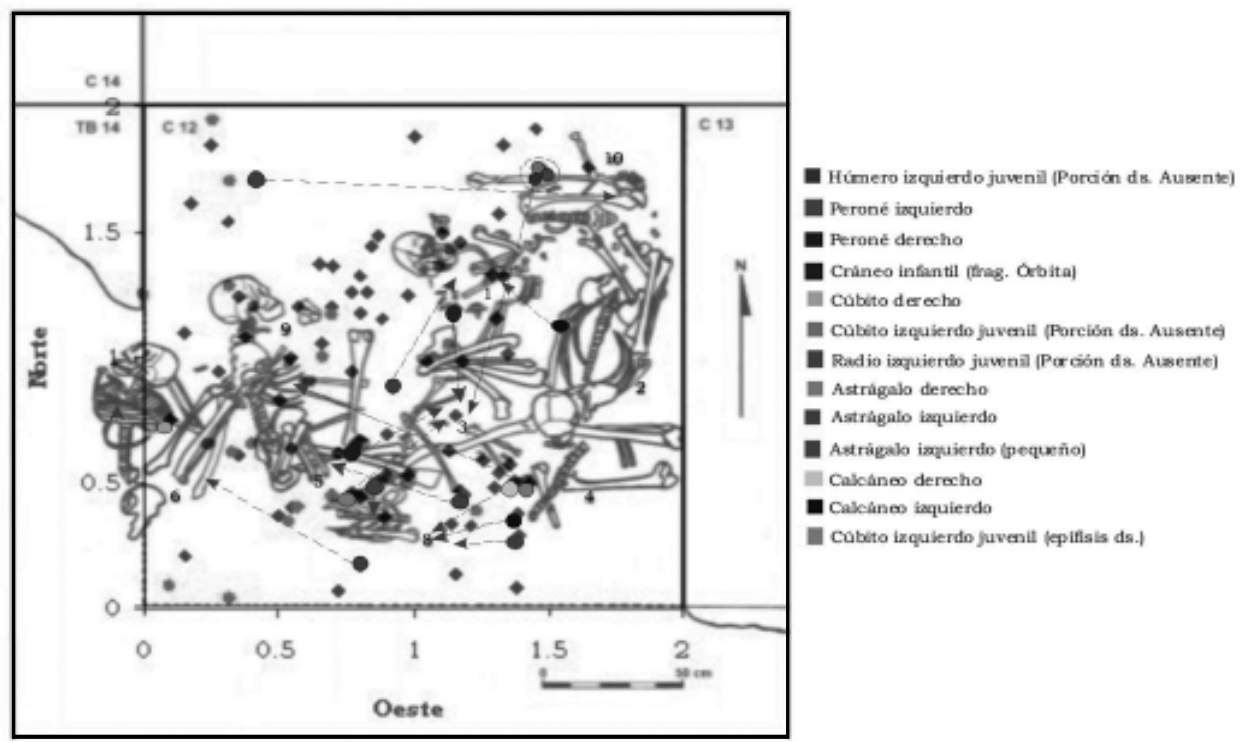

Figura 10. Gráfico de las correspondencias anatómicas determinadas en el conjunto óseo humano de TR1. 
Ambos mapeos corresponden a piezas óseas provenientes de la misma cuadrícula. Examinando las distancias entre las unidades anatómicas del GD y los esqueletos, y teniendo en cuenta la edad, sexo y tamaño de los huesos de los esqueletos, se realizaron las correspondencias anatómicas señaladas en la Figura 10. Principalmente, se logró establecer relaciones entre los individuos y ciertos huesos del tarso (astrágalos y calcáneos). También, los huesos largos de un miembro superior juvenil pudieron ser correlacionados a TR1-3 y, además, se relacionó uno de estos elementos con su epífisis distal desplazada.

De los resultados de esta metodología de correspondencias anatómicas, se concluye que los desplazamientos ocurridos fueron de dos clases; piezas esqueletarias desplazadas a cortas distancias respecto del sistema esqueletal al que pertenecían y huesos que sufrieron traslados de considerable distancia respecto del esqueleto correspondiente. Se lograron establecer 13 correspondencias anatómicas sólo con los huesos más diagnósticos y más informativos para este objetivo, en base al conocimiento de sus lateralidades, a la posibilidad de establecer relaciones de tamaño y a sus características morfológicas. Es llamativo el caso de los 3 huesos largos juveniles, fracturados a la misma altura de sus diáfisis, que se encontraron asociados entre sí pero a una larga distancia (dentro de la C12) de TR1-3, el único individuo con las características etarias a las que estos elementos podían pertenecer. Notablemente, de estos 3 huesos juveniles, 2 de ellos presentaron marcas de roedores.

Asimismo, con el fin de estimar el desplazamiento vertical de los huesos humanos en el depósito, se analizó una muestra compuesta por 74 elementos aislados del GD. De cada uno de estos se posee su ubicación tridimensional. La línea base a partir de la cual se midió el desplazamiento vertical corresponde a los $0,80 \mathrm{~m}$ de profundidad del nivel 0 de la excavación, donde empiezan a aparecer los esqueletos (Madrid y Barrientos 2000). Con estos datos se procedió a graficar las distintas ubicaciones de los huesos en relación con este "nivel 0" (Figura 11). Se observa una dispersión mayoritaria hacia los niveles superiores, de modo que el $75 \%$ de estos elementos se hallan por encima del nivel 0 . Además, se calculó el promedio de desplazamiento para estas piezas esqueletarias: 0,17 $\mathrm{m}$ (con un desplazamiento máximo de $0,8 \mathrm{~m}$ ). Este grupo óseo esta conformado por huesos y algunos fragmentos óseos que son de un tamaño ${ }^{3} 3 \mathrm{~cm}$. En la Tabla 12 se muestran los huesos representados por nivel. Aquellos huesos por debajo del nivel $0(0,80 \mathrm{~m})$ también presentan esas dimensiones $\left(\mathrm{e}^{\prime \prime} 3 \mathrm{~cm}\right)$ pero

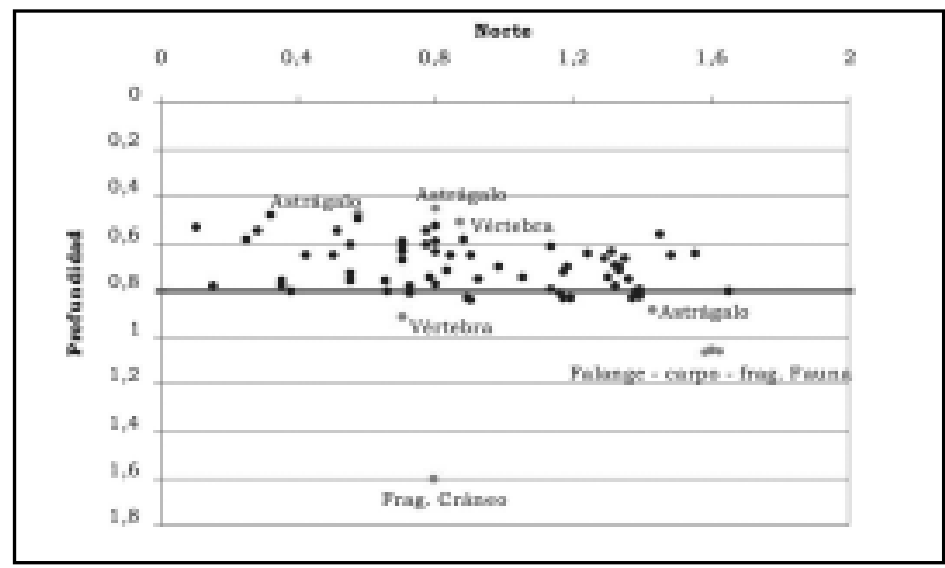

Figura 11. Distribución vertical de elementos óseos en relación al nivel 0 (Los puntos verdes señalan la ubicación del hueso nombrado). 
son escasos y se concentran entre los $0,80 \mathrm{~m}$ y $0,91 \mathrm{~m}$. Fuera de esta agrupación espacial, se encuentran 4 huesos por debajo de $1 \mathrm{~m}$ de profundidad (huesos del carpo, falange, fragmento de cráneo y fragmento óseo de fauna).

\section{Discusión}

En referencia a los índices cuantitativos del GI, de los resultados se obtiene la conclusión de que el conjunto de entierros humanos de TR1 presenta un alto grado de representación diferencial en relación con la integridad esqueletal. En efecto, el esqueleto con mayor grado de integridad, TR1-2 (NME=113), presenta alrededor de un 37\% de faltantes óseas, siguiendo en orden ascendente TR1- 6 con un 55,9\%, TR1-4 con 58,7\%, TR1-9 con $61,5 \%$ TR1-10 con $63,7 \%$, TR1-8 con 65,4\% y TR1-1 con 74,9\%. Los 3 individuos restantes (TR1-5, TR1-3 y TR17) exhiben un NME muy bajo (6, 5 y 1 respectivamente), apartándose ampliamente de los demás individuos. Estos resultados reflejan claramente la marcada representación ósea diferencial que caracteriza al conjunto de entierros humanos de TR1. Otra característica del mismo es la excelente preservación del tejido óseo en la gran mayoría de los huesos humanos. Esta última condición indicaría que los procesos diagenéticos no han incidido en la conformación cuantitativa este registro bioarqueológico. Esta observación, evidente a partir del análisis macroscópico, puede hacerse extensiva a una escala microestructural ya que existe una línea de evidencia que permite sostener esta idea: los fechados radiocarbónicos realizados sobre esqueletos de esta muestra. El material datado no presentó limitaciones con sus componentes orgánicos y minerales y, por otro lado, arrojó edades radiocarbónicas acordes con las expectativas dado el contexto arqueológico del sitio.

Para el GD, los huesos los huesos con mayor frecuencia de representación son aquellos que corresponden a manos y pies. Los elementos que corresponden a los miembros superiores son asignables a la clase de edad niñez (sensu Buikstra y Ubelaker 1994). Por tanto, se hace evidente en este conjunto que sus componentes presentan un tamaño pequeño y una relativamente baja densidad mineral ósea (Galloway et al. 1997; Suby y Guichón 2004).

Teniendo en cuenta estas características en la composición anatómica de los esqueletos, puede discutirse la integridad de este conjunto de entierros mediante el cálculo de la proporción de huesos hallados vs los esperados (índice de supervivencia). Como fuera señalado anteriormente, el registro bioarqueológico de TR1 se compone de un total de 6 individuos adultos y 4 subadultos de diferentes edades. Esta representación de individuos y de edades, haría esperable un NME total de 2016 en el caso de que todos los esqueletos estuvieran completos anatómicamente (valores de referencia: adultos= 179 elementos; juveniles $=214$ elementos; infantiles $=300$ elementos). El NME total para este conjunto óseo es 708. Por consiguiente, esta muestra representa sólo el 35,1\% del total esperado, de modo que una alta proporción de las piezas esqueletarias esperadas no está representada. Este bajo índice de supervivencia de partes óseas estaría indicando la acción de uno o más factores incidiendo en la estructuración actual de este registro. ¿Cuáles fueron estos factores?

Uno de los potenciales factores coadyuvantes a los de naturaleza tafonómica y postdepositacional es la edad de muerte de cada individuo (Gordon y Buikstra 1981). En el caso de TR1, no se observa una clara relación entre este factor y el índice de supervivencia de partes esqueletarias. Los 5 esqueletos con valores de NME más altos presentan un rango de edad muy amplio, que va desde los 16-17 años hasta los 55 años. Esto implica que la densidad 
mineral, que podría mediar en detrimento de los individuos adultos de mayor edad y de sexo femenino, no fue influyente en este caso ya que justamente el mejor representado es un esqueleto correspondiente a un individuo adulto mayor femenino. Sin embargo, puede destacarse el hecho de que los individuos con menos partes óseas representadas son subadultos (TR1-5 y TR1-3).

Por otro lado, puede concluirse que el tamaño, otra variable que puede relacionarse a la edad, fue determinante en la alteración del conjunto. Esto se evidencia en que los individuos con mayor porcentaje de elementos óseos recuperados poseen huesos con un grado completo de desarrollo estructural y de tamaño grande. Puede notarse, además, una correlación entre los individuos con menos partes óseas y el tamaño de las mismas. Tal es el caso de los esqueletos TR1-5 y TR1-3 correspondientes a individuos subadultos. En este caso podría esperarse que sus dimensiones fueran uno de los factores influyentes en esta pobre representación, lo cual pudo suceder con TR1-3 (9,5-11,5 años). No obstante, se presenta el Individuo 5 con una edad de entre 15-20 años que posee huesos comparables en tamaño a los adultos. Por consiguiente, es posible que este individuo haya sido afectado por otro/s proceso/s y/o agente/s.

Con el fin de discutir el grado de integridad del registro bioarqueológico es necesario evaluar los resultados obtenidos de la correlación entre el índice de supervivencia y los valores de DMOc obtenidos por Galloway et al. (1997). Los resultados indican la ausencia de una correlación significativa estadísticamente. Este resultado apoya lo observado en la muestra a nivel preservacional y de integridad, indicando que la composición anatómica de estos entierros no se encuentra mediada por la densidad mineral ósea. Si hubiera sido así, cabría esperar la presencia predominante de huesos caracterizados por una DMOc elevada, la cual implica un mayor potencial de supervivencia (Galloway et al.1997). No siendo este el caso en el conjunto óseo humano de TR1, puede postularse que la densidad mineral de los elementos no fue un factor influyente en la pérdida de piezas esqueletarias observada. Como ya fue mencionado, los índices de densidad mineral ósea establecidos para huesos humanos presentan la problemática de la amplia variabilidad de factores que afectan el contenido mineral óseo y, por lo tanto, que pueden incidir en los valores de DMO. En consecuencia, resulta metodológicamente difícil poder considerar todos los aspectos que introducen variabilidad en los valores del contenido mineral y, en última instancia, en los índices de DMO. De modo que se deja abierto el debate sobre este tipo de mediciones en restos óseos humanos, pero se destaca la utilidad de las mismas ya que ofrecen una herramienta útil para explorar inicialmente la existencia o no de patrones de preservación diferencial del registro bioarqueológico. Por otro lado, debe mencionarse que estos autores tomaron medidas únicamente para ciertos huesos, quedando fuera un gran número de elementos que podrían introducir variación en las correlaciones establecidas en esta investigación si se consideraran sus valores de DMOc.

La laguna pudo ser factor causante de pérdidas de elementos óseos mediante su avance y retroceso sobre la barranca (González 2006, 2007). En este sentido, analizando la ubicación de los esqueletos con respecto al borde de la laguna, se observa que los esqueletos ubicados en el borde de la laguna (TR1-4, TR1-6 y TR1-9) se encuentran entre los más altamente representados en el sitio, mientras que individuos como el 1 y el 3 , situados hacia el interior de la cuadrícula están escasamente representados. Por otro lado, los análisis tafonómicos (González 2007) no mostraron evidencias de abrasión y pulido, rasgos de la erosión hídrica, 
en ninguno de los huesos de la muestra. Esto estaría en concordancia con el hecho de que el retroceso de la línea de costa es un fenómeno reciente, si se lo evalúa desde de una cronología arqueológica. Así, en un lapso de tan sólo 10 años la laguna avanzó varios metros sobre el terreno, reflejando la posibilidad de que estos restos óseos humanos hayan sido enterrados originalmente en un sector alejado del borde, a decenas o tal vez a cientos de metros del espejo de agua. Hasta el momento, no puede descartarse la acción hídrica como posible causante de faltantes óseas. Ésta podría haber influido de manera leve en la estructuración de este conjunto óseo humano, durante la última etapa de la historia tafonómica, provocando algunas alteraciones en las disposiciones espaciales de los huesos y exposiciones en determinados casos. La forma en que este proceso actuó en épocas recientes (últimos 10 años) no fue uniforme sino que provocó modificaciones distribucionales puntuales y heterogéneas dentro de este conjunto óseo humano. Esta observación se halla apoyada por la observación actual de la variación de la línea de costa y por el hecho puntual de que, justamente el avance de la laguna fue lo que causó la exposición de parte de estos huesos (ver discusión en González 2007).

Otra de las variables evaluadas que pudo producir cambios en la composición de este registro bioarqueológico es la actividad de roedores (González 2007). A raíz de los resultados obtenidos, se planteó a manera de hipótesis que estos roedores dejaron huellas de su comportamiento mediante la alteración de las distribuciones espaciales, verticales y horizontales, de los restos óseos humanos. Aquellos huesos que conforman el GD son en su mayoría pequeños y se encontraban desplazados respecto de su posición anatómica original, tal efecto pudo ser causado por la actividad fosorial de los roedores.

En base a la información actualística (Bocek 1986; Durán 1991), se propone que la actividad de roedores pequeños (Ctenomys sp.) ha afectado en una forma exigua la conformación del conjunto óseo humano de TR1, más orientada a desplazamientos de huesos de mayor tamaño $(>5 \mathrm{~cm})$ hacia los niveles profundos como consecuencia del derrumbamiento de los túneles (ver discusión en González 2007).

Todos los elementos óseos pertenecientes al GD que presentan información sobre su ubicación tridimensional, se posicionan a partir del nivel $0,45-0,50 \mathrm{~m}$ y poseen dimensiones siempre mayores a 2,5 cm, de modo tal que se correspondería con el planteamiento que sostiene que los materiales considerados "grandes" (mayores a $5 \mathrm{~cm}$ ) se concentrarán hacia los niveles inferiores a la zona de actividad de estos roedores (30-60 cm) (Bocek 1986). En este sentido, también debe considerarse la acción de otra clase de roedor que habitó y habita en las inmediaciones del sitio, el coipo o falsa nutria (Myocastor coypus) (ver Salemme y Madrid 2007). Para el caso de los humanos, Barrientos (1997) sugirió las desarticulaciones serían el producto de la actividad de animales cavadores capaces de desplazar elementos de relativamente gran tamaño y peso (coipo). Este sería el caso de la mayor parte de los huesos que conforman el GD; es decir, piezas óseas de dimensiones mayores a las identificadas para la actividad de los tuco-tucos $(>5 \mathrm{~cm})$ (Tabla 12).

Continuando con el examen de los agentes y/o procesos que pudieron afectar el alto grado de pérdidas de piezas esqueletarias en la muestra aquí analizada, es necesario considerar la acción de otro tipo de animales, los carnívoros. Estos animales actúan sobre los huesos en superficie, de modo que su consideración en esta discusión respecto de un conjunto de entierros primarios provoca cierta confusión en una primera instancia. En esta muestra de huesos humanos se evidencia la acción de carnívoros mediante la presencia de marcas 
provocadas por su mordisqueo sobre el tejido óseo (ver González 2007). Dadas las condiciones de integridad anatómica de este conjunto, estos animales habrían actuado in situ sin afectar en gran medida la correspondencia entra las piezas esqueletarias. Debido a las características minúsculas de estas marcas y a la condición arriba mencionada, se propuso al hurón o "huroncito patagónico" (Lyncodon patagonicus) como el potencial responsable de las modificaciones registradas (para una descripción de los aspectos que apoyan esta hipótesis y una discusión sobre la posibilidad de que el comportamiento antrópico del pasado haya permitido la acción de otros agentes carnívoros ver González 2007).

Por otro lado, no puede dejar de considerarse la acción antrópica sistémica entre los posibles agentes/ procesos modificadores y causantes de pérdidas de elementos óseos. Existe la posibilidad de que los humanos hayan incidido en la configuración de este conjunto de entierros humanos de un modo no intencional, mediante la extracción de sedimento en el mismo pozo para agregar otros cadáveres. Esta acción podría implicar la presencia de varias inhumaciones en el mismo lugar. No obstante, los dos fechados realizados sobre huesos humanos apoyan la hipótesis de los dos eventos de entierro propuesta por Madrid y Barrientos (2000). Aún así, debe destacarse que la re-evaluación de los criterios tafonómicos tomados por estos autores para determinar la presencia de dos eventos no permite sostener dicha conjetura.

En este sentido, los autores sostienen que si se considera la hipótesis alternativa de que la desarticulación parcial de algunos individuos fue consecuencia de sucesivos eventos de inhumación en un espacio restringido, sería esperable una serie de modificaciones enumeradas por Ubelaker (1984). Es decir, utilizar reiteradas veces una misma área para enterrar a los muertos, en general, implicaría consecuencias tales como desarticulación de partes esqueletarias, fragmentación y destrucción o desaparición de las mismas. Madrid y Barrientos (2000) analizan las características de TR1-10, el individuo considerado como parte de un entierro previo al de los 9 restantes y depositado a mayor profundidad. Sostienen que las evidencias que sugieren la probabilidad de que haya sido enterrado anteriormente a los demás, son su mayor grado de facturación, su mayor grado de carbonatación y la ausencia de partes esqueletarias del lado derecho.

Sin embargo, los resultados de los análisis tafonómicos (ver González 2006, 2007) indican que TR1-10 no presenta el mayor índice de fracturación. Así, los resultados de la frecuencia de huesos fracturados por individuo mostraron que TR1-2 ( $\mathrm{N}=23)$ es quien posee el mayor numero siguiéndole, en orden de frecuencias absolutas descendentes, TR1-9 ( $N=22)$, TR1-4 $(\mathrm{N}=20)$, TR1-8 $(\mathrm{N}=22)$ y luego TR1-10 con un $\mathrm{N}$ de 14. Otra de las características enunciadas para TR1-10 fue la carbonatación alta. González $(2006,2007)$ detalló la frecuencia absoluta de los huesos que presentan carbonato por cada individuo. TR1-4 presenta 70 elementos óseos afectados, TR1-9 posee 61 huesos con carbonato, TR1-2 presenta 49 piezas óseas carbonatadas y, en cuarto lugar, TR1-10 con 43 elementos afectados. Finalmente, la ausencia de piezas esqueletarias también fue registrada en dicho trabajo. Así, se presentaron las frecuencias de huesos hallados por individuo y el porcentaje que representa en relación con la cantidad de huesos esperados en los esqueletos correspondientes a los 2 grupos de edad en esta muestra (adultos y subadultos). Los valores de frecuencias de partes esqueletarias muestran a TR1-3 con 2,3\%, debajo TR1-5 presenta el 2,8\% de sus elementos, continua TR11 con un $25,1 \%$ de hueso representados, luego esta TR1-8 con 34,6\% y finalmente el individuo $10 \operatorname{con} 36,3 \%$ de sus partes esqueletarias. 
Se han presentado los valores obtenidos para cada una de las características empleadas para asignar a TR1-10 a un evento diferente del resto. Según estos resultados, existen otros individuos con esas características manifestadas en mayor intensidad. Así, el que más fracturas presenta es TR1-2 y el esqueleto con mayor frecuencia de huesos "carbonatados" es TR1-4. TR1-3 es el que menos partes esqueletarias presenta; no obstante, si se lo descarta por pertenecer a la clase de edad niñez considerando que esto pudo influenciar significativamente en las pérdidas de piezas óseas, el individuo adulto que más ausencias de elementos presenta es TR1-1, siguiéndole TR1-8.

Por consiguiente, estos resultados no permiten apoyar las afirmaciones respecto de TR110 propuestas por Madrid y Barrientos (2000). No obstante, se considera que no existe evidencia suficiente como para afirmar la presencia de varios eventos sucesivos de entierro. En tal caso, si se aplicaran las mismas consideraciones enumeradas por Ubelaker (1984), podría inferirse que ocurrieron en este registro bioarqueológico varios episodios de inhumación. Sin embargo, se necesitan criterios diagnósticos más precisos para poder definir este tipo de situación en un contexto arqueológico con varios esqueletos enterrados.

Finalmente, la evaluación de la actividad antrópica actual indica que la metodología empleada en el rescate de estos restos sumada a las condiciones de riesgo (anegación) que estos presentaban para su preservación, pudieron conducir a la pérdida de ciertas unidades anatómicas durante esta labor. También las tareas extractivas, de traslado, limpieza y almacenamiento de estos materiales, han incidido en las pérdidas óseas y fracturas registradas durante este análisis Por consiguiente, los humanos contemporáneos se adicionan como otro agente tafonómico que alteró la estructura anatómica original de este conjunto y contribuyó, exiguamente, a su baja frecuencia de piezas óseas (González 2007)

\section{Conclusión}

Los entierros primarios de TR1 conforman un sólido conjunto de huesos que no han resultado altamente modificados en su superficie por procesos y/o agentes tafonómicos (González 2007). No obstante, las medidas cuantitativas indican una baja supervivencia de partes esqueletarias en relación con el NMI (10) registrado. Así, en base al análisis cuantitativo y tafonómico, es posible sostener que la principal perturbación que experimentó esta muestra fue la pérdida de elementos óseos y, en segundo lugar, el desplazamiento y la pérdida de ciertas relaciones anatómicas.

La perturbación provocada en el conjunto óseo humano puede calificarse de considerable en el aspecto distribucional. Los desplazamientos verticales y horizontales producidos llevaron a que muchas relaciones anatómicas se perdieran y en algunos casos involucraran dispersión de distancias considerables (desplazamiento vertical mínimo: $23 \pm 6 \mathrm{~cm}$, según mediciones tomadas de Madrid y Barrientos 2000). En esta investigación se plantearon una serie de correspondencias anatómicas a través del examen de los mapeos, los datos de ubicación tridimensional registrados y teniendo en cuenta las características de tamaño y edad de los huesos desplazados y su correspondiente sistema esqueletal. En este caso, no se tomaron distancias máximas y mínimas, por lo tanto las correspondencias señalan la posible relación anatómica original entre la unidad ósea desplazada y el individuo correspondiente. No se pretende con este análisis reflejar las posiciones originales exactas de las piezas movidas sino su relación con un esqueleto del conjunto. De este modo, se apoya la conclusión 
ya obtenida mediante los índices cuantitativos, que indican la pertenencia de ambos grupos de huesos (GI y GD) al mismo conjunto de entierros. Asimismo, se logró concluir que el NMI no varió al vincular los porcentajes de supervivencia por unidad anatómica de cada uno de los grupos.

\section{Agradecimientos}

En primer lugar quiero agradecer a María A. Gutiérrez y Gustavo Barrientos por su orientación en la investigación tafonómica dentro de la que se enmarcó este trabajo. A Gustavo Politis, Patricia Madrid y Gustavo Barrientos por proporcionar las evidencias con las que he trabajado. A Agustina Massigoge por su colaboración en la traducción del resumen. A Pablo Bayala por su colaboración en la revisión y edición final del trabajo. Agradezco especialmente a Cristian Kaufmann por sus acertados comentarios que ayudaron a mejorar este trabajo. Todas las ideas y conclusiones aquí vertidas son de mi exclusiva responsabilidad.

\section{Notas}

1. El cúbito infantil que representa al denominado TR1-7 (Barrientos 1997; Madrid y Barrientos 2000), es considerado aquí dentro del GD ya que cumple con las características que definen a este grupo (fue hallado en forma aislada, sin correspondencias anatómicas con un esqueleto y desplazado respecto del conjunto GI). No obstante, su inclusión en este grupo no invalida su determinación como un individuo diferente de los 9 restantes ya que así lo permiten sus características morfológicas, sus dimensiones y su grado de desarrollo ontogénico.

2. Este valor se obtuvo contabilizando cráneo y mandíbula como dos unidades separadas y excluyendo los huecesillos del oído interno.

3. Por cuestiones de espacio, en las tablas se excluyeron aquellos elementos que no poseían representación. 4. No se presenta tabla de valores para TR1-7 en el GI ya que en la contabilización fue considerado para el GD por las características antes explicadas.

\section{Biblografía}

Barrientos, G.

1997. Nutrición y dieta de las poblaciones aborígenes prehispánicas del sudeste de la Región Pampeana. Tesis Doctoral inédita. Facultad de Ciencias Naturales y Museo, Universidad Nacional de La Plata, La Plata.

Bocek, B.

1986. Rodent Ecology and Burrowing Behavior: Predicted Effects on Archaeological Site Formation. American Antiquity 51(3): 589-603.

Buikstra, J. y D. Ubelaker.

1994. Standards for data collection from human skeletal remains. Arkansas Archaeological Survey Research Series 44.

Carr, C.

1995. Mortuary Practices: Their Social, Philosophical-Religious, Circumstantial, and Physical Determinants. Journal of Archaeological Method and Theory 2 (2): 105-200. 
Durán, V.

1991. Estudios de perturbación por roedores del género Ctenomys en un sitio arqueológico experimental. Revista de Estudios Regionales 7: 7-31.

Galloway, A.; P. Willey y L. Snyder

1997. Human bone mineral densities and survival of bone elements: A contemporary sample. Forensic Taphonomy: The posmortem fate of human remain.(ed. por W. D. Haglund and M. H. Sorg), pp. 295-317. CRC Press.

González, M. E.

2006. Estudios de interés tafonómico en los restos óseos humanos de la laguna Tres Reyes 1 (Partido de Adolfo Gonzales Chaves). Aportes para el estudio de la formación de contextos arqueológicos en ambientes lagunares de la provincia de Buenos Aires. Tesis de Licenciatura Inédita. Facultad de Ciencias Sociales (UNCPBA), Olavarría.

2007. Estudios de interés tafonómico en los restos óseos humanos de la laguna Tres Reyes1 (Partido de Adolfo Gonzales Chaves). Intersecciones en Antropología 8: 215-233.

Gordon, C. C. y J. Buikstra

1981. Soil $\mathrm{pH}$, bone preservation, and sampling bias at mortuary sites. American Antiquity 48 (3): 566-571.

Grayson, D. K.

1991. Alpine Faunas from the White Mountains, California: Adpative Change in the Late Prehistoric Great Basin? Journal of Arcaheological Science 18: 483-506.

Gutiérrez, M. A.

2004. Análisis tafonómicos en el Área Interserrana (Provincia de Buenos Aires). Tesis Doctoral inédita. Facultad de Ciencias Naturales y Museo, Universidad Nacional de La Plata, La Plata.

Gutiérrez, M.A, L. Miotti, G. Barrientos; G. Mengoni Goñalons y M. Salemme 2004. Taphonomy and Zooarchaeology in Argentina En Zooarchaeology of SouthAmerica. BARF International Series. Ed. por G. Mengoni Goñalons pp. 121-142. Archaeopress, Oxford.

Klein, R. G. y K. Cruz-Uribe

1984. The Analysis of Animal Bones from Archaeological Sites. Chicago University Press, Chicago.

Kligmann, D.

1998. Procesos de formación del registro arqueológico: una propuesta alternativa a los modelos clásicos. Actas y Memorias del XI Congreso Nacional de Arqueología Argentina (8va parte). Revista del Museo de Historia Natural de San Rafael (Mendoza) XX (1/2): 123-136.

Lyman, L.

1994. Vertebrate Taphomomy. Cambridge University Press, Cambridge. 
Madrid, P. y G. Barrientos

2000. La estructura del registro arqueológico del sitio Laguna Tres Reyes 1 (Provincia de Buenos Aires): Nuevos datos para la interpretación del poblamiento humano del Sudeste de la región Pampeana a inicios del Holoceno tardío. Relaciones de la Sociedad Argentina de Antropología XXV: 179-206.

Madrid, P. y M. Salemme

1991. La ocupación tardía del sitio 1 de la laguna Tres Reyes. Partido de Adolfo Gonzales Chaves, Provincia de Buenos Aires. Boletín del Centro 3: 165-179.

Madrid, P., G. Politis, M. Leipus y C. Landini

1991. Estado actual de las investigaciones en el sitio 1 de la Laguna Tres Reyes: análisis lítico tecno-morfológico y procesos de formación de sitio. Boletín del Centro 2: 112-122.

O'Shea, J.

1984. Mortuary Variability: An Archaeological Investigation. Academic Press, Orlando.

Politis, G. G.

1988. Revisión de las unidades de análisis propuestas para representar el cambio cultural en la Región Pampeana. Precirculados del IX Congreso Nacional de Arqueología, pp. 206-218. Buenos Aires.

Politis, G. G. y P. Madrid

1988. Un hueso duro de roer: Análisis preliminar de la tafonomía del sitio Laguna Tres Reyes 1 (Pdo. de Adolfo Gonzales Chaves, Pcia. de Buenos Aires). De Procesos, Contextos y otros Hueso.(ed. por N. Ratto y A. Haber), pp. 29-44. ICA y Facultad de Filosofía y Letras (UBA), Buenos Aires.

Reitz, E. J. y E. S. Wing

1999. Zooarchaeology. Cambridge Manuals in Archaeology. Cambridge University Press, Cambridge.

Salemme, M. C.

1987. Paleoetnozoología del sector Bonaerense de la Región Pampeana, con especial atención a los mamíferos. Tesis Doctoral Inédita. Facultad de Ciencias Naturales y Museo, Universidad Nacional de La Plata, La Plata.

Salemme, M. y P. Madrid

2007. Archaeofaunas from Laguna Tres Reyes 1 site: taxonomic richness and abundance during the beginning of late Holocene in south-eastern Pampean Region (Argentina). Taphonomy and Zooarchaeology in Argentina (ed. por M.

Schiffer, M.B.

1972. Archaeological context and sistemic context. American Antiquity 37: 156-165.

1987. The nature of Archaeological Evidence, Cap. 1:3-11. Formation Process of the archaeological record. Univesity of New Mexico Press, Albuquerque. 
Suby, J. y R. Guichón

2004. Densidad ósea y frecuencias de hallazgos en restos humanos en el Norte de Tierra del Fuego. Análisis exploratorio. Intersecciones en Antropología 5: 95-104.

Tonni, E. P. y F. Fidalgo

1978. Consideraciones sobre los Cambios climáticos durante el Pleistoceno Tardío-Reciente en la Provinia de Bs. As. Aspectos ecológicos y zoogeográficos relacionados. Ameghiniana. Tomo XV, N¹-2.: 235-253.

Ubelaker, D.

1984. Human Skeletal Remains. Excavation, analysis, interpretation. Manuals on Archaeology 2. Taraxacum, Washington. 